OSTI

\title{
Independent Assessment of the Savannah River Site High-Level Waste Salt Disposition Alternatives Evaluation
}

Published December 1998 
$\cdots+, \quad, \quad+\ldots+\ldots \ldots$ 


\section{DISCLAIMER}

This report was prepared as an account of work sponsored by an agency of the United States Government. Neither the United States Government nor any agency thereof, nor any of their employees, make any warranty, express or implied, or assumes any legal liability or responsibility for the accuracy, completeness, or usefulness of any information, apparatus, product, or process disclosed, or represents that its use would not infringe privately owned rights. Reference herein to any specific commercial product, process, or service by trade name, trademark, manufacturer, or otherwise does not necessarily constitute or imply its endorsement, recommendation, or favoring by the United States Government or any agency thereof. The views and opinions of authors expressed herein do not necessarily state or reflect those of the United States Government or any agency thereof. 


\section{DISCLAIMER}

Portions of this document may be illegible in electronic image products. Images are produced from the best available original document. 


\begin{abstract}
This report presents the results of the Independent Project Evaluation (IPE) Team assessment of the Westinghouse Savannah River Company High-Level Waste Salt Disposition Systems Engineering (SE) Team's deliberations, evaluations, and selections. The Westinghouse Savannah River Company concluded in early 1998 that production goals and safety requirements for processing SRS HLW salt to remove Cs-137 could not be met in the existing InTank Precipitation Facility as currently configured for precipitation of cesium tetraphenylborate. The SE Team was chartered to evaluate and recommend an alternative(s) for processing the existing HLW salt to remove CS-137. To replace the In-Tank Precipitation process, the Savannah River Site HLW Salt Disposition SE Team downselected (October 1998) 140 candidate separation technologies to two alternatives: Small-Tank Tetraphenylborate (TPB) Precipitation (primary alternative) and Crystalline Silicotitanate (CST) Nonelutable Ion Exchange (backup alternative). The IPE Team, commissioned by the Department of Energy, concurs that both alternatives are technically feasible and should meet all salt disposition requirements. But the IPE Team judges that the SE Team's qualitative criteria and judgments used in their downselection to a primary and a backup alternative do not clearly discriminate between the two alternatives. To properly choose between Small-Tank TPB and CST Ion Exchange for the primary alternative, the IPE Team suggests the following path forward: Complete all essential $R \& D$ activities for both alternatives and formulate an appropriate set of quantitative decision criteria that will be rigorously applied at the end of the $R \& D$ activities. Concurrent conceptual design activities should be limited to common elements of the alternatives.
\end{abstract}




\section{EXECUTIVE SUMMARY}

The Independent Project Evaluation Team was chartered in April 1998 to closely follow and critically review the approach, progress, and final recommendations of the Westinghouse Savannah River Company (WSRC) High-Level Waste (HLW) Salt Disposition Systems Engineering (SE) Team. Formation of the SE Team was an important follow-on to a judgment by Westinghouse Savannah River Company in early 1998 that production goals and safety requirements for processing HLW salt to remove Cs-137 could not be met in the existing In-Tank Precipitation Facility as currently configured for precipitation of cesium tetraphenylborate. The SE Team was chartered to identify options, evaluate alternatives, and recommend an alternative(s) for processing salt to a permitted waste form.

The SE Team completed (October 29, 1998) their final report and recommended a preferred alternative (Small-Tank Tetraphenylborate (TPB) Precipitation) and a backup alternative (Crystalline Silicotitanate (CST) Nonelutable Ion Exchange). We have accomplished our chartered assessment of the SE Team's downselection through independent observation of SE Team activities, meetings and discussions with the SE Team, DOE site visits, and review of SE Team progress reports. We evaluated the SE Team's process and the results of that process to assess technical and institutional feasibility of proposed alternatives, to assess expected performance of proposed alternatives, and to review cost estimates. This report summarizes the results of our assessment.

\section{Conclusions}

Our comprehensive assessment has led to the following conclusions:

1. The SE Team used rigorous procedures and methodology to correctly downselect the alternatives from 140 to 18 , then to a short list of four alternatives, namely
a. Small-Tank Tetraphenylborate (TPB) Precipitation
b. Crystalline Silicotitanate (CST) Nonelutable Ion Exchange
c. Caustic Side Solvent Extraction
d. Direct Disposal as Grout.

2. We concur that both the Small-Tank TPB and the CST Ion Exchange alternatives are technically feasible and should meet all salt disposition requirements, including interface requirements with the Savannah River Site Defense Waste Processing Facility, Tank Farm, and Canyon Facilities.

3. Our assessment is that the SE Team's qualitative criteria and judgements used in their downselection to a primary and a backup alternative did not clearly discriminate between the two alternatives: Small-Tank TPB and CST Ion Exchange.

4. In concert with the SE Team, we are impressed with the attractive features of the Direct Disposal as Grout and Caustic Side Solvent Extraction alternatives, and we agree that these alternatives, because of either technical immaturity (solvent extraction) or likely lengthy resolution of institutional issues (grout), cannot meet current HLW system mission requirements and drivers. 


\section{Cost Considerations}

We evaluated the methodologies, bases of estimates, procedures, and systems the SE Team used to create the cost estimates recorded in their final report. Based on our evaluation, we concluded that:

1. The results of the cost estimation process described in the SE Team's final report are reasonable for the preconceptual design phase.

2. Removal of costs of the Consolidated Incineration Facility from the CST Ion Exchange alternative results in significant cost discrimination.

3. Cost optimization was not a primary consideration in any of the SE Team's deliberations and decisions.

4. More refined design data will make cost comparisons meaningful and validatable.

Because we determined that the Caustic Side Solvent Extraction and Direct Disposal as Grout options were properly eliminated from the selection process, our discussion of cost and financial issues primarily focuses on the remaining alternatives of Small-Tank TPB and CST Ion Exchange.

While the life cycle costs (LCC) forecasts are the product of a rigorous, disciplined process, the immaturity of the preconceptual design information (i.e., bases of estimates) used did not allow the SE Team to develop activity-based cost estimates that could be validated. Further, costs associated with uncertainty could not be developed with supporting rationale, calculations, and bases of estimate and flow of funds was not scheduled due to the immature nature of the preconceptual design information. This resulted in SE Team estimates that were largely level among competing technical alternatives. The level condition resulted in the SE Team assessment that cost is not a discriminating factor in the selection process. We conclude, however, that on an adjusted LCC basis, CST Ion Exchange is estimated to cost $\$ 1,178 \mathrm{M}$ less than the Small-Tank TPB alternative if Consolidated Incineration Facility (CIF) incineration operations are eliminated from the CST Ion Exchange alternative. Elimination of CIF LCC is appropriate for the CST Ion Exchange and Direct Disposal as Grout options because neither of these alternatives uses incineration. Appropriate analysis and decision cannot be made unless the effects of eliminating unnecessary activities are considered. If the CIF functions are necessary to support some waste forms, then costs associated with CIF are appropriately considered as costs of those wastes and not the HLW system.

\section{Path Forward}

We are convinced that the choice between Small-Tank TPB and CST Ion Exchange for the primary alternative should be determined by an objective procedure. We suggest that the following actions are appropriate:

1. Complete all essential research and development (R\&D) activities for both alternatives.

2. Formulate an appropriate set of quantitative criteria that will be rigorously applied at the end of the R\&D activities to choose the primary alternative.

3. Initiate the conceptual design phase but complete only those activities common to both alternatives until the primary alternative is chosen at the end of the R\&D. 
4. WSRC should continue to aggressively manage tank farm space inventory. Implementation of any of the alternatives requires maximizing existing tank space inventory.

\section{Other Considerations}

We offer three other considerations:

1. The Department of Energy should continue to pursue R\&D associated with the Caustic Side Solvent Extraction alternative. This research should be coordinated through the DOE EM30, EM-50, and Tank Focus Area organizations.

2. Direct Disposal as Grout, while technically feasible, has large uncertainties relating to institutional and regulatory issues. The alternative requires DOE policy decisions prior to any further pursuit at the Savannah River Site or at any other DOE site.

3. WSRC has initiated appropriate project management strategy for successful implementation of a project of this magnitude. This observation assumes that appropriate funding/budget resources are available.

We judge that the comprehensive systems approach employed by the SE Team is exemplary and should prove a valuable model for the complex. They have developed a solid foundation to continue the path forward. 


\section{ACKNOWLEDGMENTS}

The Independent Project Evaluation Team acknowledges the prompt, thorough, and courteous manner in which both the Systems Engineering and the DOE-SR Teams responded to our many requests for information and assistance. We also acknowledge the detailed and professional manner in which these teams addressed the issues and interacted with us both as a group and as individuals. 


\section{CONTENTS}

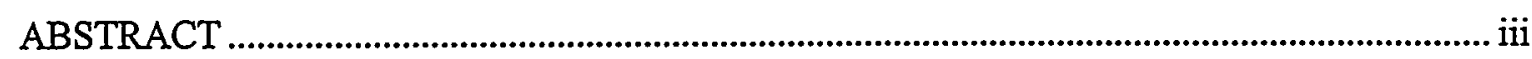

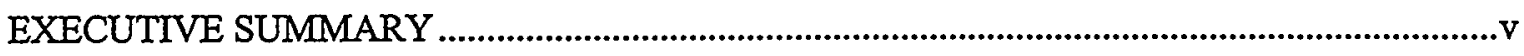

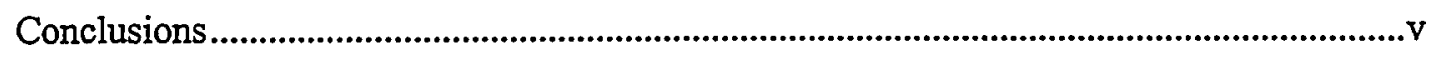



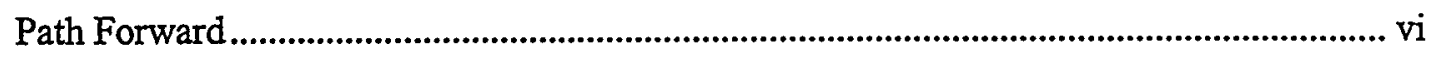

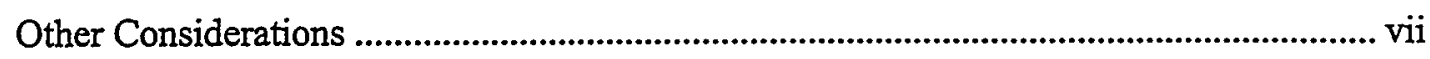



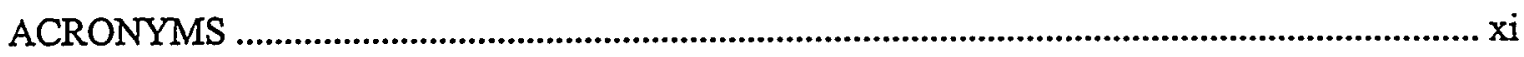



1.1 Savannah River Plant High-Level Waste System .................................................1

1.2 Systems Engineering Salt Disposition Team Charter..................................................

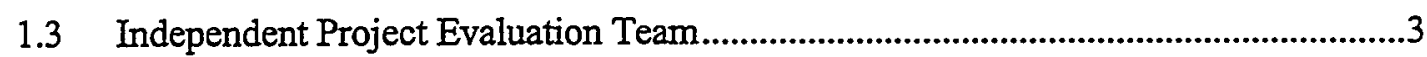

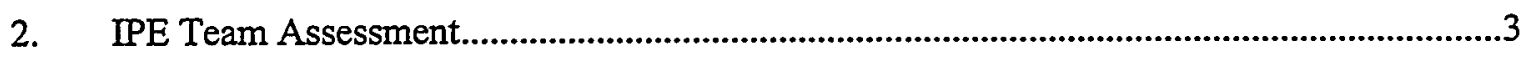

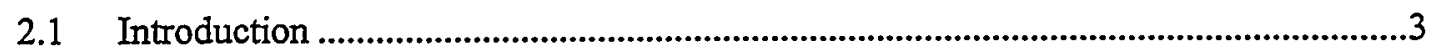

2.2 Phases I and II, Identification and Investigation ..................................................5

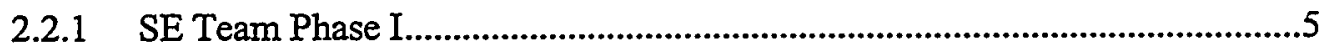

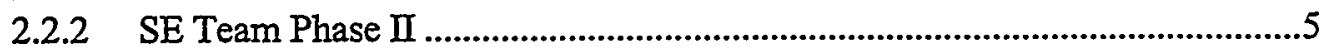



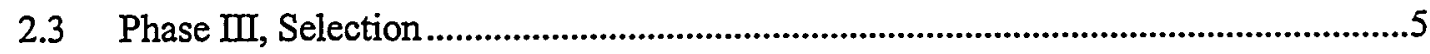

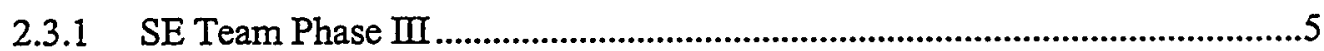

2.3.2 IPE Team Phase III Assessment .................................................................6

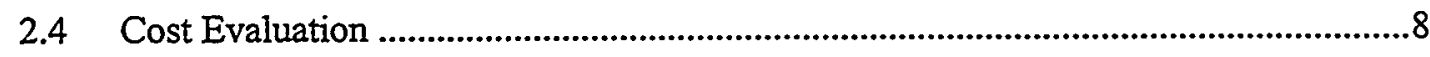



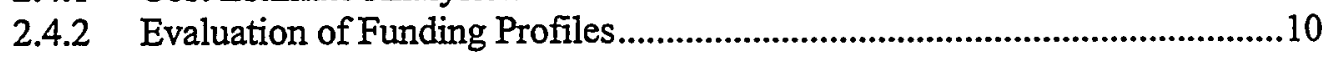

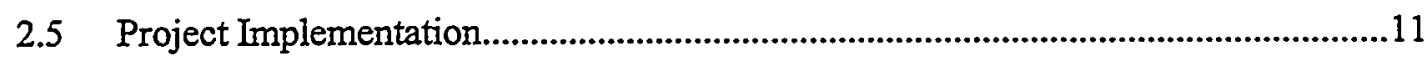

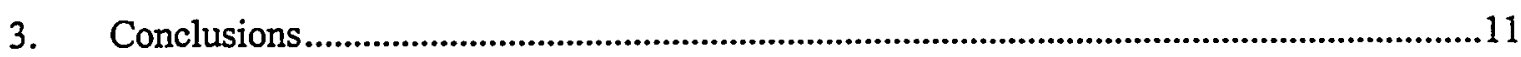


Appendix A-Independent Project Evaluation Team Members and Biographies.

Appendix B-Independent Project Evaluation Team Charter .................................................... B-1

Appendix C - Independent Project Evaluation Team Chronology of Activities .......................... -1

Appendix D—Phase I and Phase II Letter Reports ............................................................. D-1

Appendix E-Phase III Technical Evaluation............................................................................... E-1

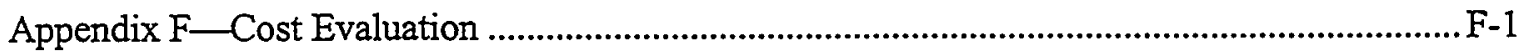

\section{FIGURES}

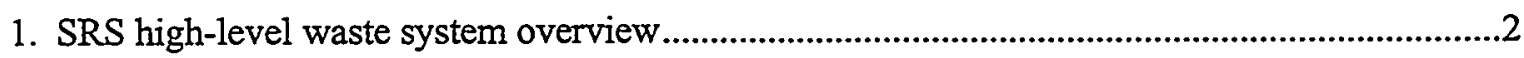







\section{TABLES}

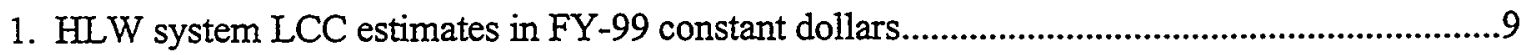

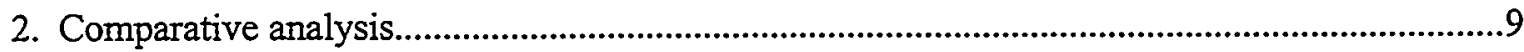




\section{ACRONYMS}

ACPC Accelerated Clean Up Paths to Closure

ANL Argonne National Laboratory

ANSI American National Standards Institute

BNFL British Nuclear Fuels Limited

BOE basis of estimates

CAB Citizens' Advisory Board

CIF Consolidated Incineration Facility

CST crystalline silicotitanate

DF decontamination factor

DNFSB Defense Nuclear Facilities Safety Board

DOE Department of Energy

DWPF Defense Waste Processing Facility

FFA/CO Federal Facility Agreement/Consent Order

FTE full time equivalent

HLW high-level waste

IPE Independent Project Evaluation

ITP In-Tank Precipitation

Kd distribution coefficient

LCC life cycle cost

LLW low-level waste

MST monosodium titanate

MTPB tetraphenylborate salts

NEPA National Environmental Policy Act

NRC Nuclear Regulatory Commission 
OPC Other Project Costs

ORNL Oak Ridge National Laboratory

R\&D research and development

ROM rough order of magnitude

SE systems engineering

SRAT Sludge Receipt and Adjustment Tank

SRTC Savannah River Technology Center

STP Site Treatment Plan

TAMU Texas A and M University

TEC total estimated cost

TPB tetraphenylborate

TPC total project cost

WSRC Westinghouse Savannah River Company 


\section{Independent Assessment of the Savannah River Site High-Level Waste Salt Disposition Alternatives Evaluation}

\section{INTRODUCTION}

An Independent Project Evaluation (IPE) Team under the leadership of Joel T. Case, High-Level Waste Division Director, DOE-Idaho Operations Office, was chartered on April 20, 1998 by the Assistant Secretary for Environmental Management to closely follow and critically review the approach, progress, and final recommendations of the Westinghouse Savannah River Company (WSRC) High-Level Waste (HLW) Salt Disposition Systems Engineering Team (SE Team). Appendix A lists team members and their biographies. The IPE Team's assessment is the subject of this report.

\subsection{Savannah River Plant High-Level Waste System}

The Savannah River Plant HLW system is a set of interconnected processes that function as one large treatment facility that receives, stores, and treats HLW and converts these wastes into forms suitable for final disposal. Figure 1 is a flow diagram of the HLW system, which includes the following major facilities and processes:

- HLW storage tanks and evaporators. There are 51 underground storage tanks that contain approximately 31 million gallons of salt waste and 3 million gallons of sludge.

- Extended Sludge Processing Facility. This facility receives the insoluble sludge layer from the tanks and washes it to remove the soluble salts and a fraction of the insoluble aluminum compounds. The washed sludge is sent to the Defense Waste Processing Facility (DWPF) for eventual processing into glass.

- Defense Waste Processing Facility. The DWPF is currently vitrifying washed sludge into a borosilicate glass but is designed to vitrify both sludge and processed salt waste.

- Effluent Treatment Facility. This facility processes various low-level waste (LLW) liquid streams.

- Saltstone Facility. This facility solidifies liquid wastes into grout for disposal.

- In-Tank Precipitation and Late Wash Facilities. These facilities were intended to remove Cs-137 from the HLW salt solution.

- Consolidated Incinerator Facility (CIF). The CIF destroys the benzene generated in the InTank Precipitation process. 


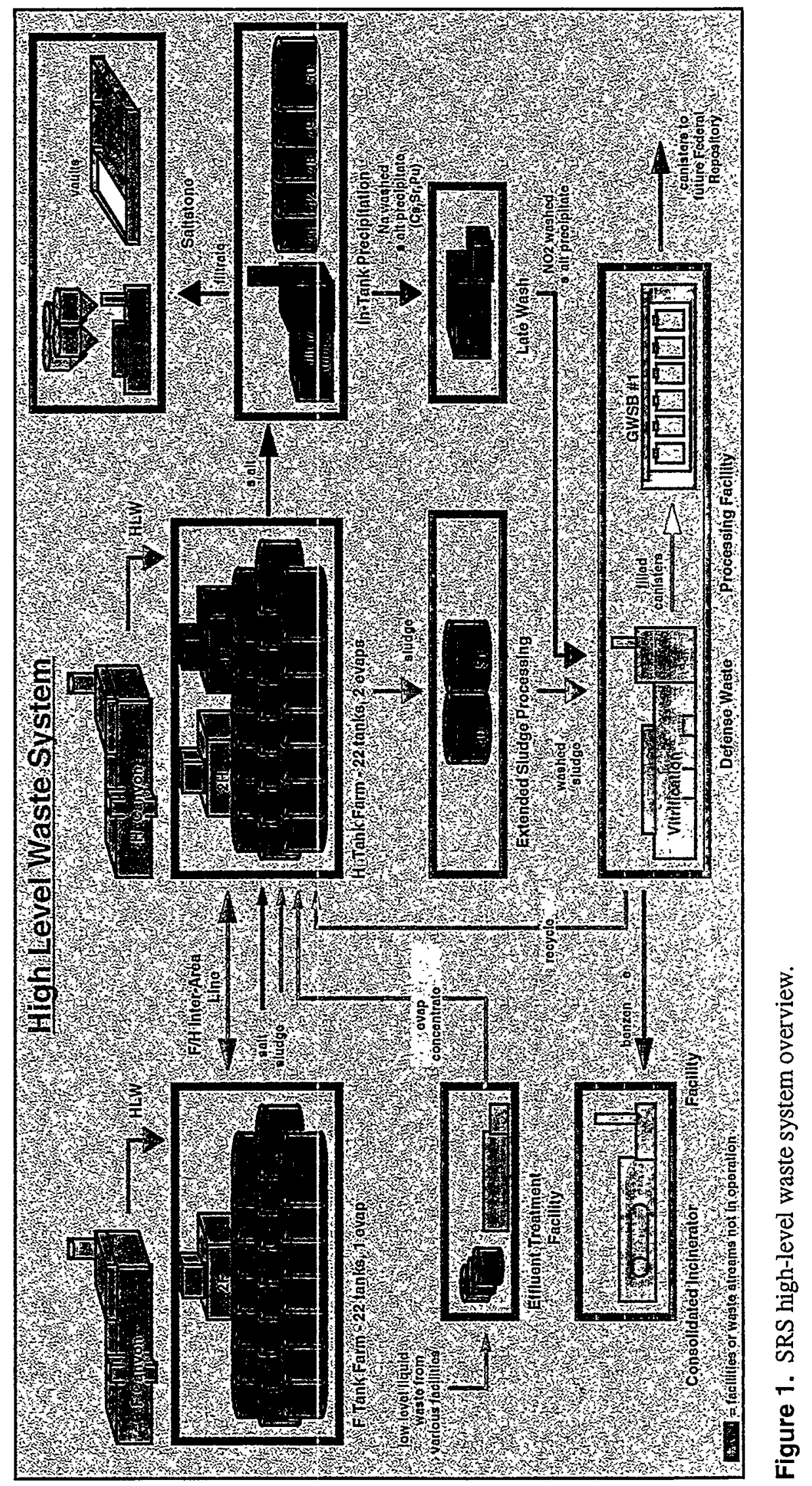




\subsection{Systems Engineering Salt Disposition Team Charter}

On March 13, 1998, the WSRC chartered the SE Team to systematically develop and recommend an alternative technology for disposition of $H L W$ salt. This evaluation was conducted using the following base assumptions:

1. Accept and process all tank farm salt waste.

2. Properly interface with all components of the HLW system.

3. Do not adversely affect operations at the SRS.

4. Meet the requirements of the Federal Facility Compliance Act Site Treatment Plan and Federal Facility Agreement/Consent Order (FFA/CO).

\subsection{Independent Project Evaluation Team}

The IPE Team was chartered on April 20, 1998 to independently oversee the systems engineering and decision processes (see Appendix B).

Specifically, our evaluation was to

- Evaluate the process used by the systems engineering team and the results of that process

- Assess the technical feasibility of the proposed alternatives

- Assess the expected performance of the proposed alternatives

- Assess the interfaces with other components of the HLW system

- Review the basis, associated uncertainties and risks, and validity of the cost estimates

- Review and evaluate the schedule and funding profile

- Evaluate the proposed project implementation.

We performed our assessment with a combination of team meetings and briefings, weekly conference calls, review of SE Team documents, technical visits to other DOE Research Laboratories, and visits to the Savannah River Site. Appendix C presents a chronology of the IPE team activities.

\section{IPE TEAM ASSESSMENT}

\subsection{Introduction}

The SE Team included members from WSRC, other DOE sites, academia, and independent consultants. The team members had experience in systems engineering, engineering sciences, science, operations, waste processing, chemical processing, process engineering, safety and regulatory, and project management. The SE Team followed the three-phase process outlined in Figure 2. The SE Team 


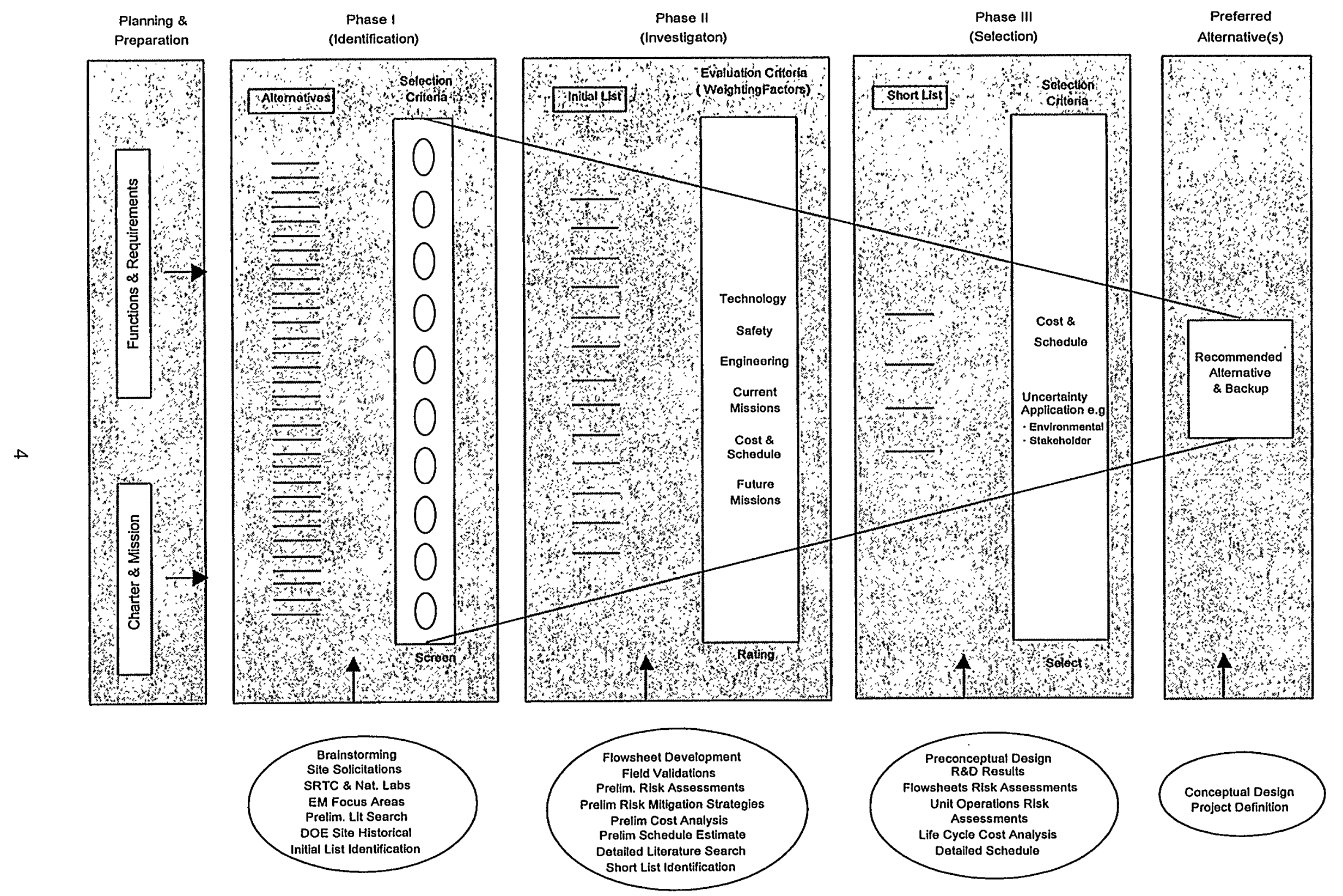

Figure 2. Selection process. (From HLW Salt Disposition Final Report Recommendation Preconceptual Design, WSRC-RP-98-00170, Rev. 0, October 29, 1998, Section 9, p. 101.) 
evaluation was bounded by key regulatory and operational constraints, including meeting all FFA/CO and STP tank closure dates, maintaining feedstock to DWPF, and continuing the capability of the tank farm to receive waste.

\subsection{Phases I and II, Identification and Investigation}

\subsubsection{SE Team Phase I}

Phase I of the SE process involved identifying and screening potential technologies for salt disposition. The SE Team Phase I Report, issued June 14, 1998 summarizes the process to identify 140 technologies and screen them to an initial list of 18 alternatives for further study in Phase II (WSRC-RP98-00162, Rev. 0, April 17, 1998). The SE Team combined features of most of the 140 technologies into 18 technologies, which were further grouped into six broad process categories: crystallization, electrochemical separation, ion exchange, precipitation, solvent extraction, and vitrification.

\subsubsection{SE Team Phase II}

Phase II was a structured evaluation of the 18 alternatives to reach a short list of four alternatives for detailed analysis in Phase III. The process included multiattribute utility analysis taking into account technology maturity, interfaces, regulatory, engineering design, and cost/schedule factors. The Phase II assessment resulted in the identification of four alternatives for evaluation (WSRC-RP-98-00165, Rev. 0, June 27, 1998).

\subsubsection{IPE Team Evaluation of Phases I and II}

Our assessment of Phases I and II is that the SE Team correctly identified a short list of four alternatives for further evaluation in Phase III. Appendix D provides the detailed results of our Phase I and Phase II assessments.

\subsection{Phase III, Selection}

\subsubsection{SE Team Phase III}

In Phase III, the SE Team used results of selected research studies of SRTC, other DOE sites, and academia to develop flowsheets, designs, and cost estimates of the four short-list alternatives.

Programmatic and technical risks and strategies to resolve the risks were used to further refine estimated costs. The SE Team eliminated the Direct Disposal as Grout alternative because of expected lengthy resolution of institutional and regulatory risks.

The SE Team concluded that cost estimates (see Figure 3) did not satisfactorily discriminate between the three remaining short-list alternatives. Accordingly, the SE Team applied engineering judgment to evaluate and compare alternatives. Attributes considered included mission, technical, environmental, engineering/design, operations, regulatory, stakeholder concerns, safety, and radiological performance.

The SE Team selected Small-Tank TPB as the primary alternative and CST Ion Exchange as the backup alternative. The SE Team eliminated the Caustic Side Solvent Extraction alternative from further consideration because of technical immaturity. 


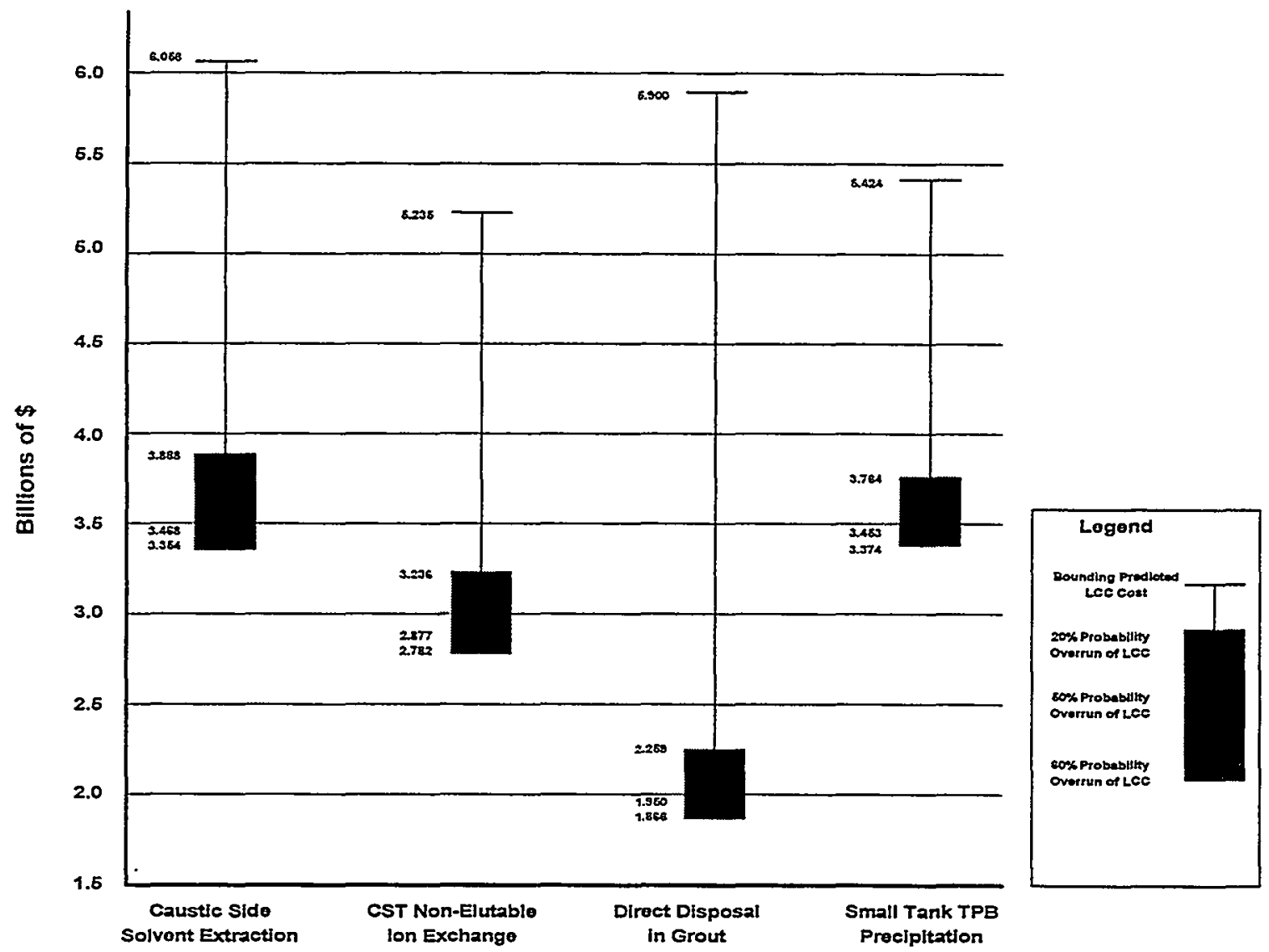

Figure 3. LCC for the four options in Phase III. (From HLW Salt Disposition Final Report Recommendation Preconceptual Design, WSRC-RP-98-00170, Rev. 0, October 29, 1998, Section 9 , p. 117.)

\subsubsection{IPE Team Phase III Assessment}

Based on our independent review, we concur that all four alternatives are technically feasible and could be implemented. However, two of the alternatives, Direct Disposal as Grout and Solvent Extraction represent unacceptably high risk alternatives for meeting current SRS High-Level Waste mission requirements. We further agree with the SE Team that Direct Disposal as Grout and Solvent Extraction were appropriately dropped from further consideration. While Direct Disposal as Grout has favorable attributes-specifically, simplicity and lower cost-this alternative requires, at a minimum, an incidental waste rulemaking and a full and successful NEPA analysis prior to title design. The schedule uncertainties associated with the Direct Disposal as Grout alternative would likely result in exceeding Tank Farm space limitations, even with aggressive management attention to institutional and regulatory issues.

We conclude that the Caustic Side Solvent Extraction alternative is technically immature. There are significant technical uncertainties related to both the extractant and the performance of the process. Further details on the technology gaps with the alternatives are included in Appendix E. 
The results of our analysis indicate that there are not sufficient data to support distinguishing between Small-Tank TPB and CST Ion Exchange as the preferred and backup alternatives.

Using the same evidence and qualitative selection criteria of the SE process, CST Ion Exchange could have been selected as the preferred alternative. The basis for this assessment includes the following considerations.

2.3.2.1 Cost. The SE Team estimates that the life cycle cost (Figure 3), for the CST Ion Exchange alternative is lower than that for the Small-Tank TPB alternative. While the SE Team considered that "... costs were similar enough not to be the prime discretionary driver in selection," we believe that the difference of approximately $\$ 600 \mathrm{M}$ in estimated life cycle costs for the two alternatives is significant.

The CIF is required for the Small-Tank TPB and Caustic Side Solvent Extraction options but not for the CST Ion Exchange option. If the CIF functions are necessary to support other waste processes, then costs associated with CIF are appropriately considered as costs of those wastes and not of the HLW system. This results in a reduction of CST Ion Exchange costs by approximately $\$ 600 \mathrm{M}$ on an adjusted LCC basis. All issues taken together represent a $\$ 1.2 \mathrm{~B}$ cost difference.

2.3.2.2 Schedule Drivers. The completion of salt waste processing for Small-Tank TPB is October 2020 for the baseline case (July 2025 with uncertainties). For CST, the baseline estimate is April 2020 (January 2025 with uncertainties). The schedule for completing salt processing is not a significantly discriminating factor. Both options start processing the salt waste in time to avoid exceeding the 2010 Tank Farm space limit assumptions.

2.3.2.3 Flexibility. The CST Ion Exchange alternative is a more flexible option. There are several potential fallback options, e.g., alternative sorbents, available in the event of failure of the CST material in an ion exchange system. No fallback options to using TPB in a continuous precipitation process have been identified.

2.3.2.4 Technical Maturity. Technical maturity was identified by the SE Team as an important qualitative criterion for selecting the preferred and backup alternatives. In their final report, ${ }^{b}$ the SE Team states that the Small-Tank TPB alternative is more technically mature than the CST Ion Exchange alternative. As described in their final report and presented to us, the Small-Tank TPB alternative involves continuous operation of a precipitation process in small stirred reactors. To our knowledge, a continuous Small-Tank TPB process has never been demonstrated on either a bench-scale or a pilot-plant scale with simulated, let alone actual, SRS salt waste. Apparently, the SE Team judgment that the SmallTank TPB alternative is technically mature is based upon extrapolation of limited plant-scale experience in operating a static Large-Tank TPB process and application of engineering models. Such extrapolation is unwarranted.

Contrary to the SE Team opinion, we believe that CST Ion Exchange technology has been brought to a high degree of technical maturity. Bench-scale tests of the CST sorbent at many DOE laboratories have been uniformly successful. Recently, a CST pilot-scale column system was used successfully at the DOE Oak Ridge site to remove Cs- 137 from about 25,000 gallons of actual site waste. Present plans at

\footnotetext{
${ }^{2}$ Westinghouse Savannah River Company, HLW Salt Disposition Final Report Recommendation Preconceptual Design, WSRCRP-98-00170, Rev. 0, October 29, 1998, p. 11.

${ }^{b}$ Ibid., pp. 129-130.
} 
the Oak Ridge site call for using the same CST columns to remove Cs- 137 from an additional 200,000 gallons of waste. Ion exchange systems and materials have also been used successfully at the DOE Hanford and West Valley sites to remove Cs-137 from large volumes of stored wastes. We recognize that these tests were not performed with SRS wastes, and technical issues remain with CST Ion Exchange; however, these issues are amenable to engineering solutions. Appendix E discusses in detail the technical attributes of both alternatives.

2.3.2.5 Safety. For the criterion of safety, the SE Team ranked CST Ion Exchange below SmallTank TPB. No satisfactory explanation for this safety ranking order is presented in the SE Team final report. The Small-Tank TPB alternative produces four moles of toxic and flammable benzene for every mole of TPB used in the process. Suitable systems must be put in place and rigorously maintained, at economic penalty, to safely contain and destroy (combust) the evolved benzene. CST and other nonelutable cesium sorbents are inorganic materials, stable to temperature and radiation, and have no potential for generating toxic benzene.

The larger question from a management perspective is why should one choose a process that generates benzene when other implementable processes are available? In addition, the principles of ISO 14000, International Organization for Standardization-Environmental Management, are to develop processes that minimize harmful effects on the environment. DOE subscribes to the principles of ISO 14000.

\subsection{Cost Evaluation}

We evaluated the financial aspects relating to the SE Team's evaluation of Salt Disposition alternatives and associated HLW System LCC at the Savannah River Site. The source of the cost information is the SE Team final report, the HLW System Plans developed in support of the SE Team report for each alternative, and other information gathered during SRS visits. Appendix F presents additional cost information for the four alternatives, including

- Cost Estimate Analysis

- Cost Optimization

- Evaluation of Schedule and Funding Profiles

- Evaluation of "Uncertainty" and Risk

- Evaluation of Bases of Estimates

- Evaluation of Cost Estimate Validity.

\subsubsection{Cost Estimate Analysis}

The SE Team provided in Table 7-14 of their final report the constant dollar LCC estimates of each of the four alternatives and their effects on the HLW System LCC. Table I summarizes the estimates and delineates line item and operating funds for each alternative and the HLW System incremental cost for each alternative.

\footnotetext{
${ }^{c}$ Ibid., p. 85.
} 
Table 1. HLW system LCC estimates in FY-99 constant dollars (amounts in millions). (Summarized from Table 7-14, WSRC-RP-98-00170.)

\begin{tabular}{|c|c|c|c|c|}
\hline $\begin{array}{c}\text { Cost Element } \\
\text { Salt Disposition Alternative }\end{array}$ & $\begin{array}{l}\text { Small- } \\
\text { Tank }\end{array}$ & $\begin{array}{c}\text { Ion } \\
\text { Exchange } \\
\end{array}$ & $\begin{array}{c}\text { Solvent } \\
\text { Extraction }\end{array}$ & $\begin{array}{l}\text { Direct } \\
\text { Grout }\end{array}$ \\
\hline Project Cost/Line Item Funds & $\$ 1,167$ & $\$ 1,294$ & $\$ 1,485$ & $\$ 997$ \\
\hline Operations Cost & 750 & 500 & 989 & 678 \\
\hline Salt Disposition Alternative LCC & 1,917 & 1,794 & 2,474 & 1,675 \\
\hline HLW System Project/Line Item Funds & 841 & 842 & 840 & 839 \\
\hline HLW System Operations Costs & 9,290 & 8,791 & 8,816 & 8,073 \\
\hline Total HLW System Incremental Costs & 10,131 & 9,633 & 9,656 & 8,912 \\
\hline Total HIW LCC System Estimate & $\$ 12,048$ & $\$ 11,427$ & $\$ 12,130$ & $\$ 10,587$ \\
\hline
\end{tabular}

Table 2 uses the information in Table 1 to compare LCC for the Small-Tank TPB and CST Ion Exchange alternatives. The analysis is limited to these two alternatives because the Direct Disposal as Grout and Caustic Side Solvent Extraction options have been eliminated from further consideration.

The first item of comparison is the difference between the line item cost of the salt disposition alternatives. As shown in Table 2, there is a \$127M difference in favor of Small-Tank TPB over CST Ion Exchange for line item project costs. When the part of the cost due to operation of the salt disposition alternatives is considered, the difference favors CST Ion Exchange by $\$ 123 \mathrm{M}$. When the HLW System

Table 2. Comparative analysis (millions of constant dollars).

\begin{tabular}{|c|c|c|c|}
\hline Salt Disposition Alternative & Small Tank & $\begin{array}{c}\text { Ion } \\
\text { Exchange }\end{array}$ & Difference \\
\hline Project Cost/Line Item Funds & $\$ 1,167$ & $\$ 1,294$ & $(\$ 127)$ \\
\hline Operations Cost & 750 & 500 & 250 \\
\hline Salt Disposition Alternative LCC & 1,917 & 1,794 & 123 \\
\hline HLW System Project/Line Item Funds & 841 & 842 & (1) \\
\hline HLW System Operations Costs & 9,290 & 8,791 & 499 \\
\hline Total HLW System Incremental Costs & 10,131 & 9,633 & 498 \\
\hline Total HLW LCC System Estimate & 12,048 & 11,427 & 621 \\
\hline CIF Life Cycle Operation Costs & 0 & $(557)$ & 557 \\
\hline Adjusted LCC & $\$ 12,048$ & $\$ 10,870$ & $\$ 1,178$ \\
\hline
\end{tabular}


incremental costs are included, the difference becomes $\$ 498 \mathrm{M}$ in favor of the CST Ion Exchange alternative. Taken together, the total differences in life cycle costs are $\$ 621 \mathrm{M}$ in favor of CST Ion Exchange. The difference between the alternatives is further increased when CIF operations are recognized. The SE Team has confirmed that CIF operations of \$557M in LCC applies only to the SmallTank TPB, not to the CST Ion Exchange alternative. The SE Team inclusion of CIF operating costs in both estimates is inappropriate. Eliminating CIF costs and reducing CST Ion Exchange LCC brings the total difference to $\$ 1,178 \mathrm{M}$ lower LCC for the CST Ion Exchange alternative. We consider $\$ 1,178 \mathrm{M}$ to be a significant cost difference.

\subsubsection{Evaluation of Funding Profiles}

A detailed funding profile analysis is contained in the Appendix $F$ to this report. Figure 4 summarizes the funding deficits for each alternative by year using the adjusted SRS Accelerated Clean Up Paths to Closure (ACPC) as the baseline. The ACPC has been adjusted to reflect a FY $1999 \$ 25 \mathrm{M}$ incremental increase, and the current FY 2000 Savannah River budget has replaced the published ACPC value for that year. The net effect of actual FY 1999 funding adjustments is not known at this time and has therefore not been included. Note that the funding shortfalls for CST Ion Exchange and Direct Disposal as Grout could be reduced in years subsequent to FY 2000 if CIF operations are not included.



Figure 4. SRS HLW system funding shortfalls. 


\subsection{Project Implementation}

As part of its charter, the IPE team was to review and assess the adequacy of management arrangements to accomplish the scope of work, as developed by the SE Team. The SE Team focused its evaluation on the technical, programmatic and cost aspects for recommending an alternative(s). Project implementation was not identified as a key attribute in the evaluation and selection phase. It is a base assumption by the SE Team that the project can be implemented by the WSRC.

DOE-SR and WSRC recognize that project management of large projects at SRS has been an ongoing concern. Inadequate up-front project planning, decision-making based on incomplete understanding of technical issues, interference with schedule and mission drivers, and lack of project ownership are areas of concern.

In acknowledgement of project management shortcomings at SRS, DOE-SR issued a Project Management and Improvements Plan (PMIP) in July 1998. They also requested that WSRC prepare a supporting PMIP to improve the project management process at SRS. WSRC issued its project management improvement plan to DOE and WSRC Management on August 28, 1998. The plan defines improvement actions, responsibility for these actions, and schedules for implementation.

WSRC is currently proceeding on the SE recommendation for salt disposition, with Small-Tank TPB as primary and CST Ion Exchange as a backup alternative. As part of implementation of the recommendation, the SE Team is transitioning into the conceptual design phase. This phase will be managed as a project. Discussions between WSRC senior management and the IPE Team indicate that many of the PMIP key elements are embodied in the SE project. Our assessment of the proposed project organization indicates this to be a fact.

WSRC has implemented a project concept for proceeding with the salt disposition SE Team recommendation. This structure should enhance success to meet the salt disposition requirements. However, we are still concerned that project end dates and mission needs related to the HLW program at SRS are still driving the decision making process for project implementation. Adequate project end dates and mission requirements clearly allow for thorough evaluation of both alternatives prior to final selection.

\section{CONCLUSIONS}

Our assessment of the WSRC HLW salt disposition SE Team alternative evaluation is that the process was exemplary. The evaluation leading to the SE recommendation was comprehensive, disciplined, correctly structured, and used the necessary resources both within and outside the DOE complex. The IPE team was impressed with this effort, and we commend the SE Team.

The IPE Team agrees with the selection of Small-Tank TPB and CST Ion Exchange alternatives. However, we do not agree with the selection of Small-Tank TPB as the primary alternative and CST Ion Exchange as the backup alternative. The qualitative criteria and engineering judgment used by the SE Team are not sufficient to discriminate between these two alternatives.

\footnotetext{
Ambrose L. Schwallie, president, Westinghouse Savannah River Company, letter to Gregory P. Rudy, manager, Department of Energy Savannah River Operations Office, August 28, 1998.
} 
The elements necessary for determining a final alternative, in particular those addressing technical uncertainties of both alternatives, have been identified by the SE Team. Completion of the key elements of this work would provide a final selection basis. Our assessment is that there is sufficient time to complete this effort without impacting the current SRS HLW system mission. Conceptual design elements common to both alternatives should proceed in parallel with the technical workscope.

Our evaluation confirms that the Direct Disposal as Grout and the Caustic Side Solvent Extraction alternatives were appropriately eliminated from further consideration. 


\begin{abstract}
Appendix A
Independent Project Evaluation

Team Members and Biographies
\end{abstract}




\section{Appendix A}

\section{Independent Project Evaluation Team Members Biographies}

\begin{tabular}{ll} 
& IPE Team Members \\
Mr. Joel T. Case - Team Leader & Department of Energy \\
Dr. Harry Babad & Technical Consultant \\
Mr. Jerald Barbre & Program Analyst \\
Mrs. Genene A. Fife & Administrative Support \\
Dr. Dieter A. Knecht & Consulting Scientist \\
Dr. Leroy C. Lewis & Scientific and Engineering Fellow \\
Dr. Dade W. Moeller & Nuclear Consultant \\
Mr. James A. Murphy & Consulting Systems Engineer \\
Mr. David R. Pack & Administrative Support \\
Mrs. Mindy L. Renfro & IPE Review Team Coordinator \\
Mr. Wallace W. Schulz (Wally) & Nuclear Consultant \\
Dr. Lawrence L. Tavlarides (Larry) & Professor of Chemical Engineering \\
Dr. Donald E. Wood (Don) & Nuclear Consultant \\
\hline
\end{tabular}




\section{Joel T. Case}

Mr. J. T. Case is currently the Division Director for High-Level Waste Programs at the U.S. Department of Energy Idaho Operations Office. In this capacity, Mr. Case provides management oversight of high-level waste treatment and storage activities at the Idaho National Engineering and Environmental Laboratory.

Mr. Case has approximately 18 years work experience in the Federal and commercial sector in the areas of nuclear safety, environmental protection, and waste management. Mr. Case has a Bachelor's Degree in Microbiology and a Master's Degree in Nuclear and Environmental Engineering from the University of Florida.

\section{Harry Babad}

Dr. H. Babad has 25 years experience as an internationally recognized multidisciplinary team leader in the areas of nuclear waste treatment and disposal, characterization, safe storage, strategic planning, and technical and regulatory issue resolution and closure, and in developing and implementing associated major program technical strategies. He has over 17 years experience in Industrial Research and Development in applied R\&D, hazardous wastes treatment and disposal, and new products/process development. He has been active in interdisciplinary and multidisciplinary functional and peer reviews of waste management, environmental, and safety documentation for Department of Energy (DOE) and ACEL.

Dr. Babad received his Bachelor's Degree in Chemistry, Polytechnic Institute of Brooklyn, 1956; and his Masters and Doctorate in Organic Chemistry, with a Minor in Analytical Chemistry from the University of Illinois, 1961. 


\section{Jerald Barbre}

Mr. J. Barbre has over 25 years of experience in project management in both the private and Federal sectors. His experience is primarily in the area of financial analysis and includes project scheduling and budget analysis. Mr. Barbre is currently the Program Analyst for the Department of Energy-Idaho Operations Office Waste Management Program. In this capacity, he participated in two major Source Evaluation Boards as the Financial Advisor.

From 1973 to 1987, Mr. Barbre was employed by the Union Pacific Railroad Company where he held positions as Project Schedule Manager and Budget Manager for the Motive Power and Machinery Department in Pocatello, Idaho. In 1987, he was employed by the Defense Contract Audit Agency (DCAA) where he was Auditor in Charge over major contractors at Vandenburg Air Force Base. In 1989, Mr. Barbre worked for Delco System Operations in Goleta, California, where he was in charge of the development of Indirect Rate Proposals used in pricing all government contracts and was appointed as the contact for all interface activities with DCAA. In addition to his regular duties with the Waste Management Program, he has participated in the DOE-Headquarter's sponsored complex-wide LowLevel Waste Cost Team, was Project Manager for cost impact evaluation and implementation of DOE Order 435.1 (Waste Management Order) at the Idaho National Engineering and Environmental Laboratory.

Mr. Barbre has a Bachelor's Degree in Accounting Information Systems from Idaho State University. He was vice-president of Beta Alpha Psi - National Honor Fraternity of Accountancy. He is a member of the Institute of Internal Auditors.

\section{Dieter A. Knecht}

Dr. D. A. Knecht is currently a Consulting Scientist with Lockheed Martin Idaho Technologies Company at the Idaho National Engineering and Environmental Laboratory. In this capacity, he provides technical support in the High-Level Waste Program, Plutonium Focus Area, and research activities.

Dr. Knecht is a recognized expert on high-level waste technologies, regulations, and policies. He has 30 years of experience with over 60 publications and four patent disclosures. He provided technical and management direction to develop glass and glass-ceramic waste forms for Idaho National Engineering and Environmental Laboratory high-level waste liquid and calcine. He developed a process for encapsulating radioactive krypton-85 in zeolite for long-term storage in support of the nuclear fuel cycle. He provided krypton storage facility design support to DOE and IAEA programs. He has held complex-wide committee memberships in areas of waste acceptance, quality assurance, fissile material supply, and modeling. He was technical program chair for ANS-sponsored topical meeting, Spectrum '92 and was co-editor of 1995 MRS Proceedings on Scientific Basis for Nuclear Waste Management. He is a member of the statewide Idaho National Engineering and Environmental Laboratory Citizen Advisory Board.

Dr. Knecht has a Bachelor's Degree in Chemistry from Oberlin College and a Doctorate in Physical Chemistry from the University of Rochester, with postdoctoral research experience at the National Research Council of Canada and University of Minnesota. 


\section{Leroy $C_{\text {. Lewis }}$}

Dr. L. C. Lewis has 31 years experience in the nuclear industry in technical and management positions. He has experience in the chemistry and engineering of nuclear fuel storage, fuel reprocessing, radioactive waste processing and management, and D\&D of nuclear facilities. He has been directly involved in process development activities for fuel reprocessing at the Idaho Chemical Processing Plant. He was the team leader for the liquid metal processing during the D\&D of Experimental Breeder Reactor I. For approximately twenty years, he was the manager of the Analytical Chemistry Laboratories at the Idaho Chemical Processing Plant. During that time, he was actively involved in designing the state-ofthe-art Remote Analytical Laboratory. He is currently involved in placing spent fuel in dry storage. He is also the Idaho National Engineering and Environmental Laboratory contact person for management of U-233 fuel.

Dr. Lewis received his Bachelor's Degree from the College of Idaho in Chemistry and Mathematics. He received his Doctorate in Physical Chemistry from Oregon State University. He is currently a scientific and engineering fellow for Lockheed Martin Idaho Technologies Company in Idaho Falls, Idaho. He has approximately 70 publications and three patents. He is an adjunct professor of chemistry for the University of Idaho.

\section{Dade W. Moeller}

Dr. D. W. Moeller attended college at the Georgia Institute of Technology where he received a Bachelor's Degree in Civil Engineering and a Master's Degree in Environmental Engineering. He received a Doctorate in Nuclear Engineering from North Carolina State University. He retired in June 1993 as Professor Emeritus in Environmental Health from the faculty of the Harvard School of Public Health, where he had served for 15 years as Chairman of the Department of Environmental Health Sciences, followed by 12 years as Associate Dean for Continuing Education. Prior to joining the Harvard Faculty, he served for 18 years as a commissioned officer in the U.S. Public Health Service.

From 1973 to 1988, Dr. Moeller served as a member of the Advisory Committee on Reactor Safeguards (he chaired the Committee in 1976), and from 1988 through 1993, he served as Chairman of the Advisory Committee on Nuclear Waste, U.S. Nuclear Regulatory Commission. In 1997, Dr. Moeller was elected an honorary member of the National Council on Radiation Protection and Measurements, after having served as a member of the Council from 1967 to 1997 . He is a member of the National Academy of Engineering, past President of the National Health Physics Society, and a fellow in the American Nuclear Society and the American Public Health Association. In addition, he is a registered professional engineer, is certified by the American Board of Health Physics, and is a diplomat in the American Academy of Environmental Engineers. He has published over 200 scientific papers and is the author of a textbook on Environmental Health, the second edition of which was published by Harvard University Press in 1997.

Dr. Moeller has numerous awards amongst which are the Distinguished Achievement Award, Health Physics Society, and the Meritorious Achievement Award, U.S. Nuclear Regulatory Commission. He currently serves as President of Dade Moeller \& Associates. 


\section{James A. Murphy}

Mr. J. A. Murphy has 16 years experience in the Nuclear Industry as a chemist and systems engineer. He was an analytical chemist and supervisor in the Analytical Chemistry Laboratories at the Idaho Chemical Processing Plant and was actively involved in the development of remote analytical instruments and the start up of the Remote Analytical Laboratory. He was the group leader for studies on waste form acceptance of the glass-ceramic waste form developed at the Idaho Chemical Processing Plant. He has performed systems analysis studies on sodium waste treatment, high-level waste calcination and tank farm management. He has been the team leader to develop a Federal Facilities Compliance Act Facility Planning Model and was involved in the National Spent Nuclear Fuel systems analysis. He has been the lead systems engineer for DOE complex integration activities in high-level waste management, spent nuclear fuel management, environmental restoration, and low-level and mixed low-level waste.

Mr. Murphy received his Bachelor's Degree in Chemistry and Biology from the College of Idaho and his Master's Degree in Chemistry from the University of Idaho. He has twenty publications and one patent. He has received numerous corporate and DOE awards for technical innovation. He is currently a Consulting Systems Engineer for Lockheed Martin Idaho Technologies Company in Idaho Falls, Idaho.

\section{Wallace W. Schulz}

Mr. W. W. Schulz is a recognized world-class authority on nuclear chemical separations and waste disposal with 48 plus years of broad experience-all parts of the back-end of the nuclear fuel cycleacquired with several contractors to the Department of Energy. Wally is a highly qualified technology evaluator and analyzer who can provide valuable and authoritative counsel on nuclear waste management/disposal and chemical separation technology to government, industrial, and academic organizations. Wally is an excellent communicator and mentor with an extensive publication record. Currently, he is president of his own consulting firm based in Albuquerque, New Mexico.

\section{Lawrence L. Tavlarides}

Dr. L. L. Tavlarides received his degrees in Chemical Engineering at the University of Pittsburgh, has worked in industry as an engineer, and has been a consultant for major chemical and food industries as well as the Department of Energy throughout his career. He was a Professor of Chemical Engineering at Illinois Institute of Technology for twelve years and currently teaches at Syracuse University where he served as chairman of the Chemical Engineering Department and Associate Dean of the College of Engineering. Among his honors are Fellow of American Institutes of Chemical Engineers, the Chancellor's Citation Award in Academic Achievement, and Affiliated Staff Scientist at Pacific Northwest National Laboratories. Professor Tavlarides has over 150 publications, including 10 patents in the areas of solvent extraction, mixing of liquid-liquid dispersions, synthesis of absorbents for heavy metal separations, supercritical fluid technology, and instrument development 


\section{Donald E. Wood}

Dr. D. E. Wood is a consultant in Risk and Performance Assessment, Regulatory Analysis, and Health Physics. He recently retired from Westinghouse Hanford Company after 18 years of service in Waste Management aspects of safety and risk assessment. Earlier, he spent 15 years at Kaman Sciences Company in Safety Analysis, Neutron Activation Analysis, Nuclear Weapons Shielding, and Neutron Generator Development. Previous to that, he was employed by the General Electric Company at Hanford in Shielding and Reactor Physics.

Dr. Wood holds a Bachelor's Degree from the University of Nevada and a Bachelor's Degree and Doctorate Degree from Northwestern University. He is a fellow of the American Physical Society, holder of an IR-100 Award, and is listed in Who's Who in the West. As a Senior Advisor at Westinghouse Hanford Company, he has chaired or served on numerous advisory committees, including the Department of Energy Performance Assessment Task Team, the Washington State Science Advisory Board, and the Westinghouse Hanford Company. Safety and Environmental Council. 
Appendix B

Independent Project Evaluation Team Charter

James M. Owendoff Memorandum to Joel T. Case, Department of Energy, EM-32, April 20, 1998 


\section{memorandum}

DATE: April 20, 1998

REPLY TO

EM-32

ATTN OF:

subject: Independent Assessment of the Savannah River Site High-Level Waste Salt Processing Project

The purpose of this memorandum is to follow up on my request that you organize and lead an independent assessment of the Savannah River Site (SRS) High-Level Waste (HIW) Salt Processing Project.

A major component of the SRS HLW mission is to receive, store, treat, and stabilize highly radioactive waste from processed spent nuclear fuel and defense waste. Salt disposition is a key element supporting this mission. The HLW System is currently configured to process salt through the In-Tank Precipitation (ITP) process resulting in two waste streams. The high activity waste stream will be transferred to the Defense Waste Processing Facility (DWPF) for vitrification and the low activity waste stream will be transferred to the Saltstone Facility for final disposal. Technical issues associated with the ITP process have led the Department of Energy to direct Westinghouse Savannah River Company (WSRC) to perform an evaluation of salt disposition alternatives using a systems engineering approach.

You arẹ requested to form an Independent Project Evaluation (IPE) Team, reporting to me, to provide independent oversight of the WSRC Systems Engineering (SE) Team efforts during the alternatives analysis and planning phases. As such, the Team will conduct periodic peer reviews during the WSRC alternatives evaluation and recommendation process.

As part of its efforts, the IPE Team will be requested to evaluate the process used by, and results of, the SE Team to assess the technical feasibility and expected performance of the . proposed alternative(s) and interfaces with DWPF and other HLW system operations. Also, the Team will be requested to review the cost estimates developed by the SE Team, understand the basis for the estimates, identify uncertainties and associated risks, and judge the overall validity of the estimates. Cost optimization should also be considered. The schedule and related funding profile should be evaluated. The manner in which the HLW salt processing project will be accomplished, including how it will be managed, should be evaluated and assessed. In summary, the IPE Team is to review and assess the technical feasibility of achieving the proposed goals of the HLW salt processing project, interface with other SR HLW operations, the credibility of the associated cost and schedule estimates, and the adequacy of management arrangements to accomplish the scope of work, as developed by the SE Team. 
Please provide me with status briefings as appropriate, and a final report on your findings by October 19, 1998. You should coordinate the development of your team and proposed methodology with Thad Konopnicki to ensure adherence to the objectives of the National Research Council report on Independent Assessments.

By copy of this memorandum, the Office of Waste Management and Savannah River Operations Office are directed to support you in whatever ways that are required to make this a successful endeavor.



James M. Owendoff

Acting Assistant Secretary for Environmental Management

cc:

M. Frei, EM-30

R. Erickson. EM-32

T. Konopnicki, EM-40

G. Rudy, SR

R. Schepens, SR

J. Wilcynski, ID 


\section{Appendix C}

\section{Independent Project Evaluation Team Chronology of Activities}


C-2 


\section{Appendix C}

\section{Independent Project Evaluation Team Chronology of Activities}

During the course of its review, IPE Team members participated in the following activities in order to obtain background information, to understand the supporting research and development activities, and to follow the decision-making process.

Table C-1. Team activities.

\begin{tabular}{|c|c|c|c|}
\hline Date & Place Visited & Team Member & Description \\
\hline $5 / 19 / 98$ & Savannah River Site & Joel Case & $\begin{array}{l}\text { Initial briefing for IPE Team leader on the SE } \\
\text { Process. }\end{array}$ \\
\hline $5 / 20 / 98$ & Washington, D.C. & Joel Case & $\begin{array}{l}\text { Met for preliminary discussions with James M. } \\
\text { Owendoff, Acting Assistant Secretary for } \\
\text { Environmental Management, U.S. DOE. }\end{array}$ \\
\hline $\begin{array}{l}6 / 29 / 98 \\
7 / 2 / 98\end{array}$ & Savannah River Site & IPE Team & $\begin{array}{l}\text { Initial meeting of the IPE Team for briefings on } \\
\text { the IPE process and the salt disposition work. }\end{array}$ \\
\hline $8 / 3-5 / 98$ & Las Vegas, NV & IPE Team & $\begin{array}{l}\text { Meeting to prepare the IPE Team report on } \\
\text { Phase II. }\end{array}$ \\
\hline $8 / 10-11 / 98$ & Washington, D.C. & Joel Case & $\begin{array}{l}\text { Met with EM-1, EM- } 30 \text { to discuss IPE Team } \\
\text { Status. Attended DFNSB briefing by WSRC } \\
\text { on } 96-1 \text {. }\end{array}$ \\
\hline $8 / 24-28 / 98$ & Savannah River Site & IPE Team & $\begin{array}{l}\text { Review of Phase II and the down-selection to } \\
\text { the final four alternatives. }\end{array}$ \\
\hline 9/9-11/98 & $\begin{array}{l}\text { Argonne National } \\
\text { Laboratory }\end{array}$ & $\begin{array}{l}\text { Joel Case } \\
\text { Dieter Knecht }\end{array}$ & $\begin{array}{l}\text { Review of pilot plant work on alkaline side } \\
\text { solvent extraction and initial examination of } \\
\text { accompanying data. The trip coincided with a } \\
\text { similar review by several members of the Salt } \\
\text { Disposition Team from SRS. }\end{array}$ \\
\hline $9 / 23-24 / 98$ & Savannah River Site & $\begin{array}{l}\text { Dieter Knecht } \\
\text { Don Wood }\end{array}$ & $\begin{array}{l}\text { Attended meeting of DOE and contractor } \\
\text { management on SE Process. }\end{array}$ \\
\hline 9/29/98 & $\begin{array}{l}\text { Argonne National } \\
\text { Laboratory }\end{array}$ & $\begin{array}{l}\text { Leroy Lewis } \\
\text { Wally Schulz } \\
\text { Larry Tavlarides }\end{array}$ & Follow-up review of solvent extraction $R \& D$. \\
\hline $10 / 5-8 / 98$ & Savannah River Site & $\begin{array}{l}\text { Joel Case } \\
\text { Harry Babad } \\
\text { Jerald Barbre } \\
\text { James Murphy } \\
\text { Larry Tavlarides }\end{array}$ & $\begin{array}{l}\text { Review and discussions of cost estimating } \\
\text { process. }\end{array}$ \\
\hline $10 / 15 / 98$ & $\begin{array}{l}\text { Oak Ridge National } \\
\text { Laboratory }\end{array}$ & $\begin{array}{l}\text { Joel Case } \\
\text { Dieter Knecht } \\
\text { Leroy Lewis } \\
\text { Wally Schulz } \\
\text { Larry Tavlarides }\end{array}$ & $\begin{array}{l}\text { Review of CST R\&D work that was taking } \\
\text { place. Also discussed work on solvent } \\
\text { extraction. }\end{array}$ \\
\hline
\end{tabular}




\begin{tabular}{|c|c|c|c|}
\hline Date & Place Visited & Team Member & Description \\
\hline $10 / 19-22 / 98$ & Savannah River Site & IPE Team & $\begin{array}{l}\text { Meeting to review the Phase III process and the } \\
\text { selection of the alternate and the backup to be } \\
\text { pursued. }\end{array}$ \\
\hline $10 / 21 / 98$ & Washington, D.C. & Joel Case & $\begin{array}{l}\text { IPE Team status briefing with EM-I and } \\
\text { EM-30. }\end{array}$ \\
\hline $12 / 2-7 / 98$ & Savannah River Site & IPE Team & $\begin{array}{l}\text { Meeting to prepare final report on IPE Team's } \\
\text { findings. Presented observations and } \\
\text { recommendations to the SRS Salt Disposition } \\
\text { Team. }\end{array}$ \\
\hline $\begin{array}{l}\text { Every } \\
\text { Thursday }\end{array}$ & & IPE Team & $\begin{array}{l}\text { Conference calls were held weekly with all of } \\
\text { the team members. During these calls the } \\
\text { business of the team was conducted which } \\
\text { included assignments for various team } \\
\text { members, reports by team members and other } \\
\text { business. }\end{array}$ \\
\hline
\end{tabular}




\section{Appendix D}

\section{Phase I and Phase II Letter Reports}




$$
\text { D-2 }
$$


To: James Owendoff

From: Joel Case

Date: July 13,1998

Subject: Savannah River High Level Waste Salt Disposition Independent Project Evaluation Team Initial On-site Visit, June 29- July 3, 1998

The Independent Project Evaluation (IPE) Team has initiated its review of the SRS HLW Salt Disposition Alternatives Evaluation Project. The IPE Team conducted its initial site visit on June 29 through July 2,1998 . The purpose of the site visit was to provide the Westinghouse HLW Disposition Systems Engineering Team the IPE team comments on their Phase I report, obtain an overview of the SRS HLW system, the alternatives evaluation project, and the Phase II activities, and, based upon the IPE initial review, provide Westinghouse and DOE-SR staff "preliminary" feedback concerning the Phase II assessment. A copy of the site visit agenda is attached.

\section{Background}

The SRS HLW Salt Disposition Alternatives Evaluation Project is being conducted in three phases: Phase I is an identification and screening of alternative technologies for salt disposition; Phase II is a preliminary technical and programmatic risk assessment of alternatives carried forward from the Phase I review; and Phase III, a detailed evaluation of a short list of technologies identified in Phase II to identify a recommended alternative(s) for implementation.

The team received the Phase I report for its review on June 14. The stated intent of the Phase I report is to summarize the processes used by the Westinghouse Systems Engineering Team to systematically develop alternative methods or technologies for final disposition of HLW salt. The report also summarizes the processes utilized to reduce the total list of identified alternatives to an initial list for further evaluation. This further evaluation is conducted in Phase II of the project.

To date, the Westinghouse team has identified approximately 130 alternatives that have been screened down to an initial list of 18 alternatives for further study in Phase II. It is important to note that the majority of the 130 alternatives can be grouped under broader technology categories. In Phase I, the approximately 130 alternatives was evaluated against a set of minimum screening criteria. The result of this screening exercise was an initial list of 18 alternatives for further evaluation. These 18 alternatives were grouped under the following technology categories: Crystallization, Electrochemical Separation, Ion Exchange, Precipitation, Solvent Extraction and Vitrification. These activities are documented in the report "HLW Salt Disposition Alternative Identification Preconceptual Phase I Summary Report" WSRC-RP-9800162, April 17, 1998.

Westinghouse notified the IPE Team on June 30 that the Phase II assessment of the 18 alternatives had been completed on June 27, 1998. The results of the Phase II assessment are documented in a six-volume report that was provided to the team during our visit. The results of the Phase II assessment identified four alternatives for a detailed evaluation during Phase III. These alternatives are Direct Disposal as Grout; Small Tank ITP; Non-elutable lon Exchange (glass/ceramic waste form); and Caustic Side Solvent Extraction. 
Independent Project Evaluation Initial Assessment

Outlined below are the IPE Review Team assessment of the Phase I report and Phase II activities. The team assessment of Phase II activities is based upon presentations provided by the Westinghouse Systems Engineering Team and discussions with their team members during our site visit.

Phase I report

The process that was used to identify, evaluate and screen the identified alternatives is not clearly presented in the report. The IPE Team's main concern is that the evaluation process, as currently presented in the Phase I report, would not be readily defensible or withstand scrutiny by parties not intimately involved in the project. The Westinghouse team did state during our visit that many of our team's specific comments related to this concern are addressed in the Phase II report which is currently under review by the IPE team.

The suite of technologies identified from the Phase I activities (approximately 130 alternatives) appears to be encompassing. The downselect from approximately 130 to 18 alternatives also appears to result in a reasonable suite of alternatives. However, as previously stated, the Phase I report does not clearly document how the alternatives were identified and the decisionmaking process utilized to eliminate or group alternatives.

Phase II activities

The IPE did not provide any formal comments to Westinghouse concerning the Phase II activities. The IPE team spent approximately two days with the Westinghouse Team on briefings concerning the Phase If activities and the 18 alternatives evaluated in Phase II. The Phase II report will be formally reviewed by the IPE Team starting the week of $7 / 6$ with formal comments to Westinghouse by $8 / 10 / 98$.

The initial IPE Team assessment of the Phase II results, identification of four alternatives for detailed evaluation, is that the four alternatives being carried forward are reasonable. The team will complete a detailed review of the Phase II report by July 29 .

Other Review Activities

Two members of the IPE team, Joel Case and Dieter Knecht, attended a meeting of the SRS Citizens Advisory Board subcommittee on the ITP alternatives evaluation. The subcommittee was established to monitor the ITP alternatives evaluation and provide DOE and Westinghouse feedback from the CAB on the evaluation. The subcommittee seemed very knowledgeable of the issues and seemed satisfied with the progress to date. However, it was not clear how the Westinghouse Systems Engineering Team will address significant comments or concerns raised by the CAB or other stakehoiders.

\section{Overall Impressions}

Westinghouse is using a structured systems approach in addressing the alternatives evaluation. The IPE team is concerned that documentation of the process and results is not well presented in the project report (Phase I report). However, the evaluation to date appears to encompass 
the appropriate technologies. The remaining four alternatives to be carried forward appear reasonable.

The aggressive schedule for the evaluation effort is a concern of the IPE Team. Any time constraints and/or drivers that are placing demands on the schedule for completing review and evaluation, and the subsequent design, construction, and operation of the modified or replacement process for the ITP system should be made clear. At the present time, the factors driving the schedule are not clear to the IPE Team. As noted below, the Westinghouse Team has determined that they are currently four weeks behind the original preliminary schedule.

The IPE team did find noteworthy that the current process for separations, In-Tank Precipitation, was not carried forward for evaluation. The evaluation process identified too many issues and uncertainties with the current situation to warrant further efforts.

\section{Next Steps}

DFNSB briefing by DOE and Westinghouse, July 21 in Washington, D.C. I will attend to answer any questions or provide information to the DFNSB on the IPE review.

Status briefing to Mr. Owendoff, July 21 in Washington, D.C.

Phase II report IPE review complete, July 29. Comment review meeting to consolidate IPE review comments, August 3-5, Las Vegas. Comments will be provided to SRS by August 10.

Issues

The SRS HLW Salt Disposition Alternatives Evaluation Project is currently four weeks behind schedule. The IPE team will work with SRS to make the appropriate adjustments to our review schedule and activities. Pending identification of any significant issues from the IPE Phase II report review, the next on-site visit will be focused on the Phase III activities. The IPE project Plan will be amended to reflect the revised schedule.

\section{Cc:}

Thad Konopnicki

Mark Frei

Ralph Erickson

Kurt Fisher

Jerry Lyle

Jim McCullough

Steve Piccolo

IPE Team 
Date: September 1, 1998

Subject: Savannah River High Level Waste Salt Disposition Independent Project Evaluation Team Phase II Review and Assessment (OPE-WM-98-98)

To: James Owendoff

The Independent Project Evaluation (IPE) Team has completed its review and assessment of the Savannah River Site High Level Waste Salt Disposition Systems Engineering (SE) Team Phase II activities. Phase II was a structured evaluation of the 18 "Initial List" alternatives, resulting from the Phase I Technology Identification process, to reach a "Short List" of alternatives that will be analyzed in more detail during Phase III. Phase II can be characterized as a structured evaluation of alternatives taking into account technology (maturity), mission interface, regulatory (ES\&H), engineering design, and cost/schedule.

The primary focus of the IPE Team review was the six volume report "High Level Waste Salt Disposition Alternatives Identification Preconceptual Phase II Summary Report, WSRC-RP98-00165, Revision 0, June 27, 1998." The purpose of the report was to summarize the process used to identify the Short List alternatives that will be evaluated during Phase III and to document the results of the selection process.

The IPE team initiated review of the Phase II report during the week of July 6, 1998. A team meeting was conducted August 3-5, 1998 in Las Vegas to compile the team comments and prepare an initial assessment of the Phase II process and results. Individual team member comments have been provided to WSRC and DOE-SR at their request. The attachment is the summary report of our Phase II review and assessment. The following major points resulted from our review.

- The four alternatives being carried forward as a result of the Phase Il assessment have been correctly identified. These four alternatives are Direct Disposal as Grout, Nonelutable Ion Exchange, Caustic Side Solvent Extraction, and Small Tank In-tank Precipitation.

- The Westinghouse Systems Engineering (SE) Team did a thorough evaluation of the 18 alternatives, understood enough of the chemistry, physics, and science for all 18 alternatives, to properly down-select to the final four alternatives.

- Documentation of the Phase II process and results is cumbersome and is not readily understandable to someone not involved in the process. The IPE Team strongly recommends that the excellent work done to date in Phase I and Phase II be captured in a 20-30-page overview report. This will be important for defending to outside interests the results of the SE Team actions.

- Cost was not a primary driver for discriminating between technologies for Phase II. Phase III activities will include a thorough cost evaluation. 
- There is concern that the alternatives evaluation process used by the SE Team does not allow sufficient time for applied research, development and pilot work to be factored into the decision-making process e.g., "schedule ahead of science". This will be a key IPE Team review criterion in Phase III.

- Stakeholder, including regulatory, input should be a key factor in further down-selection of the four selected alternatives during Phase III.

- The decision to drop the current separation process, Large Tank ITP, is valid. The risks and work arounds necessary to address both the chemistry problems and operational issues associated with Large Tank ITP would in all likelihood not meet the mission objectives.

The next steps for the IPE Team is to begin our assessment of the Phase III activities. Phase III of the Salt Disposition Systems Engineering Process will focus on the final selection of a preferred alternative(s). As such, the Phase III selection process will encompass a more detailed life cycle cost analysis, programmatic risk evaluation, flowsheet development for preconceptual design, limited research and development activities, and detailed schedule evaluation. The IPE Team review of Phase III will focus on the proposed cost and schedule estimates, HLW system interfaces (DWPF and Canyon Operations), results of the research and development activities and how these results are factored into the proposed alternative(s), life cycle cost and schedule estimates, and assess the uncertainties and associated risks (technical and institutional) for the selected alternative(s).

Please call me at (208) 526-6795 if you have any questions concerning our assessment to date or the attached report.

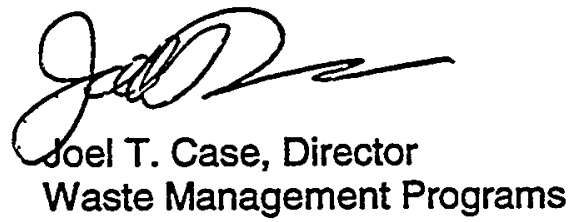




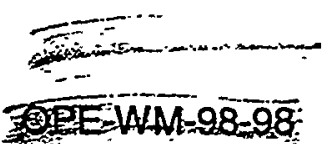

EXTERNAL DISTRIBUTION:

Thad Konopnicki, DOE-HQ

Mark Frei, DOE-HQ

Ralph Erickson, DOE-HQ

Kurt Fisher, DOE-HQ

Alice Williams, DOE-ID

Jim McCullough, DOE-SR

Steve Piccolo, WSRC

IPE Team

ID DISTRIBUTION:

CONCURRENCE:

\section{RECORD NOTES:}

1. This memo was written to transmit comments and summary report of Phase II review and assessment.

2. This memo was written by Joel Case.

3. This letter/memo closes CATS number NA

4. The attached correspondence has no relation to the Naval Nuclear Propulsion Program. Naval Reactors concurrence is not required.

JCASE, 6-6795, rscheets, 9/1/98, OPE-WM-98-98JC.doc 
Independent Project Team (IPE) Team High Level Waste Salt Disposition Phase II Assessment

Summary

The Independent Project Evaluation (IPE) Team conducted a review of the Savannah River Site (SRS) High Level Waste Salt Disposition System Engineering (SE) Team Phase Il activities and results. The purpose of Phase II was to provide a preliminary risk analysis and engineering flowsheet evaluation of the 18 alternatives resulting from Phase I and to down-select to a "Short List " of alternatives for further evaluation in Phase III. The primary focus of the IPE Team review was the six volumes report "HLW Salt Disposition Alternatives Identification Preconceptual Phase II Summary Report, WSRC-RP-98-00165, Revision 0, June 27, 1998". The IPE Team initiated its review of the Phase II report on July 6, 1998. An IPE Team meeting was held August 3-5, 1998 in Las Vegas, Nevada to compile the team comments and prepare an initial assessment of the Phase II process and results. The following key items were identified from the IPE Team review.

- The four alternatives being carried forward for further evaluation in Phase III have been correctly identified. These alternatives are Direct Disposal as Grout, Small Tank In-Tank Precipitation (ITP), Non-elutable lon Exchange, and Caustic Side Solvent Extraction.

- The Westinghouse Savannah River Company (WSRC) Systems Engineering (SE) Team did a thorough and systematic evaluation of the 18 alternatives in order to down-select to the four alternatives.

- Documentation of the Phase Il process, as provided in the six volumes report, was cumbersome and not readily understandable to someone not involved with the project. A concise summary report should be prepared (20-30 pages) for explaining the process to outside interests.

- Cost was not a primary discriminating factor for Phase II. Phase III activities will include a thorough cost evaluation

- It is not clear at this time to the IPE Team that the alternatives evaluation process allows sufficient time for applied research, development and pilot work to be factored into the decision-making process ("schedule ahead of science"). This will be a key IPE Team Phase III review area.

- Stakeholder input will be a key factor regarding decisions with the four selected alternatives; in particular with the Direct Disposal as Grout alternative.

- The decision to drop the current separation process, Large Tank In-Tank Precipitation, is valid.

A thorough discussion of the IPE Team assessment is provided in this report.

\section{Background}

The Westinghouse Savannah River Company (WSRC) has been conducting a formal structured evaluation of High Level Waste salt disposition alternatives. This evaluation, initiated in March 1998 , is to identify, evaluate and provide a recommendation of a preferred method for disposition of High Level Waste Salt at SRS. An Independent Project Evaluation (IPE) Team, reporting to DOE EM-1, was formed to provide an independent oversight of the WSRC alternatives evaluation process. This report provides the IPE Team assessment of the WSRC Phase II activities. 
The WSRC alternatives evaluation process is being conducted through a WSRC led Systems Engineering (SE) Team. The evaluation is a three phase process: Phase I of the alternatives evaluation process primarily focused on identification of potential alternative concepts, and the identification and application of screening criteria to screen down to an "Initial List" of alternatives for further evaluation in Phase II. Phase II of the alternatives evaluation was a structured evaluation of the "Initial List" of alternatives resulting from Phase I. This evaluation provides a down-select to a "Short List" of alternatives for further evaluation. Phase II can be characterized as a structured evaluation of the Initial List of alternatives taking into account technology, mission interface, regulatory (ES\&H), engineering design, cost and schedule. Phase III will provide an evaluation of the Short List of alternatives from Phase II and recommend an alternative(s) for implementation.

Phase I identified approximately 140 alternatives and provided a preliminary screening evaluation of those alternatives. The resultant output from Phase I was the down-select of the approximately 140 alternatives to 18 alternatives (the Initial List). The IPE Team assessment of the Phase l activity was provided to EM-1, DOE-SR and WSRC on July 13, 1998 (Joel Case memorandum to James Owendoff, "Savannah River High Level Waste Salt Disposition Project Evaluation Team Initial On-site Visit, June 29-July 3, 1998, July 13, 1998"). Phase II provides a disciplined analysis of the 18 Initial List alternatives and resulted in a Short List of alternatives to be carried forward in Phase III. The four Short List alternatives resulting from the Phase II evaluation are Direct Disposal as Grout, Small Tank ITP, Non-elutable lon Exchange, and Caustic Side Solvent Extraction.

The IPE Team initiated their review of Phase II activities during the team's initial on-site visit on June 29 through July 3,1998 . The on-site visit included briefings by the WSRC SE Team to the IPE Team regarding Phase II. The six volumes report "High Level Waste Salt Disposition Alternatives Identification Preconceptual Phase II Summary Report, WSRC-RP-98-00165, Revision 0, June $27,1998^{\prime \prime}$ was provided to the IPE Team upon conclusion of the on-site visit. The IPE assessment of Phase II is primarily based upon this report, information provided during the on-site visit, and individual discussions between IPE Team members and SE Team participants.

The IPE Team completed its review of the Phase II process and results on July 28, 1998. An IPE Team meeting was held August 3-5, 1998 in Las Vegas, Nevada to compile the team comments and prepare an initial assessment of the Phase II process and results. A representative from both the WSRC SE Team and DOE-SR attended to provide clarification and answer any questions the team had regarding Phase II activities. This report provides the IPE Team assessment of Phase II.

\section{IPE Phase II Assessment}

Each member of the IPE Team provided comments to the IPE chairman. These individual comments were the basis for the IPE Team discussions during the Las Vegas meeting. These comments were used to develop an overall team assessment of the Phase II process and results. The IPE Team member's individual review comments were transmitted to DOE-SR, at their request, (OPE-WM98-97, letter to Jim McCullugh, dated 8/12/98) for information only. The IPE Team does not require any response to address the comments.

The results of the IPE Phase II assessment are discussed below. 
1.The WSRC SE Team Phase II evaluation utilized a structured and thorough approach in evaluation of the 18 alternatives. The results of this evaluation, while documented in a cumbersome and hard to follow methodology (this observation is discussed in item 2 of this section), have correctly identified the appropriate alternatives for further evaluation under Phase III.

The range of processes represented by the 18 alternatives evaluated in Phase II capture the most mature and potentially applicable technologies to address salt disposition. In simple terms, the 18 alternatives can be grouped into five process categories: a.) Ion Exchange, b.) Solvent Extraction, c.) Precipitation, d.) Direct Disposal, and e.) Miscellaneous. The process used by WSRC in Phase II resulted in a down-select to four alternatives with one candidate from each of the first four groups. The two alternatives associated with the miscellaneous grouping, Fractional Crystallization and Electrochemical Separation and Destruction, can be readily dismissed from further evaluation due to technology immaturity and uncertainty. While the IPE Team determined that the SE Team utilized a complicated and hard to understand process to down-select from 18 to 4 alternatives process, the four alternatives represent application of good engineering judgement and conservatism. A second attribute that supports selection of the four alternatives is that three of the alternatives, Non-elutable lon Exchange, Small Tank ITP, and Caustic Side Solvent Extraction, with slight modifications to the flowsheets, would support the other alternatives within a grouping if it becomes necessary or desirable to choose one of these latter alternatives. This flexibility provides an important "comfort zone" in the decision-making process.

2. Documentation of the Phase II process and results provided in the six volumes report is cumbersome and difficult to understand.

While this observation appears to be "editorial" in nature and not relevant to the IPE review, the IPE Team strongly believes that a concisely written record of the decision-making process used to select the final alternative(s) is necessary to justify the process to both internal and external stakeholders. The over 3000 pages contained in the Phase II report is not well organized, contains many redundancies, and requires the reader to search through the documents to understand the problem statement, mission objectives, functional and operational requirements, system interfaces, and critical assumptions used in the evaluation. A summary report should be prepared that provides a complete and unambiguous record of all important assumptions and decisions, description of the risk assessment methodology, and how the outcomes of these efforts were used in deriving the results and conciusions. Such traceability is necessary for the defensibility of the process and results.

\section{Cost was not a discriminatory factor in the Phase II assessment.}

An important aspect of the IPE Team review is to review the cost estimates developed by the SE Team, understand the basis for the estimates, identify uncertainties and associated risks, and judge the overall validity of the estimates. Cost optimization is also a consideration of the IPE review.

For the Phase II evaluation, the WSRC SE Team developed "coarse" cost and schedule estimates using parametric procedures. The basis of estimates consisted primarily of the scaling of existing facilities and operations that the SE Team considered sufficiently similar to the alternatives to allow development of the unrefined estimates. Since Phase II was defined by the WSRC SE Team as a further refinement of the technology evaluation, cost was not strongly 
weighted in the evaluation process (approximately 12\%). Because cost was not of primary importance in the down-select process, the cost estimates provided in Phase II are not considered of a budget quality that allows for financial analysis. However, for purposes of meeting the Phase II objectives, the cost estimates associated with the alternatives evaluation are credible.

Discussion with the WSRC SE Team indicate that the Phase III evaluation of the four alternatives should result in more refined and reliable financial and cost information. The IPE Team is concerned that the level of technical maturity associated with each of the four alternatives carried forward for Phase III will effect the Teams' ability to validate the cost and schedule estimates. A key attribute of the IPE Team review will be to assess if the Phase III evaluation adequately identifies and addresses these uncertainties in developing the cost data and appropriately incorporates risk as an estimator factor.

4. Integration of Research and Development and other applicable information/data into the alternatives evaluation decision-making process is not well defined or understood based upon the IPE Team review of information to date.

The Phase I and Phase II process did a thorough job of identifying information related to HLW salt disposition processes and technologies. This included a detailed literature survey, visits to DOE sites dealing with high activity wastes, an on-site visit to the BNFL Sellafield site, and discussions with national labs and DOE's Office and Science Technology (OST). The WSRC SE Team is to be commended for taking a corporate approach in performance of the evaluation. In addition, the WSRC SE Team has identified and begun implementation of a technology test program to gather additional data to support selection of a final alternative(s) in Phase III. The IPE Team was provided a preliminary listing of these tasks during the IPE Team meeting in Las Vegas on August 3, 1998. The results from these programs are all scheduled to be conducted and completed during the Phase III evaluation. A key concern of the IPE Team is that the aggressive schedule for these testing programs may not provide sufficient information to allow for a well informed decision regarding the preferred alternative(s). The IPE Team has discussed this concern with the WSRC SE Team. The SE Team has acknowledged this concern and has stated that one aspect of the Phase III recommendation will be the identification of data and information gaps and a proposed program for addressing them, i.e., further testing, R\&D, pilot development etc. A key attribute of the IPE Team Phase III review will be an assessment of this area.

5. Stakeholder involvement regarding the alternatives evaluation has been limited. Stakeholder input will be a key factor regarding decisions concerning the four alternatives to be evaluated during Phase III, in particular the Direct Disposal as Grout alternative.

Interaction with external stakeholders during the Phase I and II process has been primarily conducted through the SRS Citizens Advisory Board (CAB) ITP Focus Group and informal discussions with both the State of South Carolina and Nuclear Regulatory Commission. The CAB ITP Focus Group is monitoring the alternative evaluation process and receives formal briefings from DOE-SR and WSRC SE Team on a regular basis. Feedback from both the CAB and regulatory entities has been favorable through Phase II. WSRC and DOE-SR recognize that the Phase III evaluation will require more focused discussions with both internal and external stakeholders. In particular, this will be a critical factor in evaluating the Direct Disposal as Grout alternative. While the Direct Disposal as Grout alternative represents a "least cost, most technological mature" option, this alternative entails potentially large institutional and regulatory risks. 
6. The decision to drop Large Tank ITP from further consideration is valid.

The SE Team did include variations of the current Large Tank ITP process in the Phase II assessment. These variations are the ITP Enhance Safety Features, Catalyst Removal ITP, and Reduced Temperature ITP alternatives. In addition, efforts have been ongoing to gain a better understanding of the chemistry of the ITP process, in particularly in the identification of the key factors that control/influence the generation and release of benzene. Evaluation of the Large Tank ITP variations, in conjunction with the results of studies to understand ITP chemistry, indicate that these alternatives exhibit a high amount of uncertainty as compared to the four alternatives selected for further evaluation and therefore, were appropriately dropped from further consideration. 


\section{Appendix E}

\section{Phase III Technical Evaluation}


E-2 


\section{Appendix E}

\section{Phase III Technical Evaluation}

This appendix summarizes the IPE Team's technical review of the SE Team Phase II alternatives of Small-Tank Tetraphenylborate (TPB), CST Nonelutable Ion Exchange, Caustic Side Solvent Extraction, and Direct Disposal as Grout and presents the bases for the IPE Team assessment of the technical feasibility of the alternatives.

The process is summarized, which includes a flow diagram and the chemistry. The status of each alternative is then discussed in regard to its attributes (merits), research and development results, technology gaps, and research and development needs. The narrative presents the basis for the IPE Team's assessment that (1) a clear distinction between the top two alternatives (Small-Tank Tetraphenylborate and CST Nonelutable Ion Exchange) cannot now be made from existing information, and (2) significant amounts of applied $R \& D$ and engineering analysis are needed to overcome shortfalls in existing chemistry, physics, and processing information shortfalls.

This appendix suggests a prioritized list of the R\&D needs that the IPE Team recommends as necessary to complete the selection between Small-Tank TPB and CST Ion Exchange. Such information is not deemed necessary for Caustic Side Solvent Extraction and Direct Disposal as Grout since these were appropriately dropped from selection, and none is provided for Direct Disposal as Grout. However, key R\&D needs are provided for Caustic Side Solvent Extraction since the IPE Team considers this alternative to have potential implementation elsewhere in the Complex. An overview of institutional concerns for the Direct Disposal as Grout alternative are included.

\section{E-1. THE SMALL-TANK TETRAPHENYLBORATE PROCESS}

In the Small-Tank TPB process, soluble radioactive ions (e.g., strontium, cesium, uranium, and plutonium) are precipitated with sodium TPB or adsorbed onto monosodium titanate. The separation process also traps any suspended sludge solids contained in the water soluble waste fraction during filtration steps. The resulting precipitate, which contains most of the radionuclides, is filtered to concentrate the solids. The moist precipitate is sent to the salt cell in the Defense Waste Processing Facility (DWPF) for pretreatment prior to incorporation into glass. The decontaminated salt solution (filtrate) containing primarily the sodium salts of hydroxide, nitrate ions, and nitrite is transferred to the Saltstone Facility for conversion to a grouted waste form. This alternative option replaces batch precipitation in Tank 48 with a continuous process in new smaller temperature-controlled stirred tanks.

The proposed process involves the following steps (see Figure E-1):

- Fresh waste from the tank farm is fed into the first vessel of a sequence of three (or at a minimum, two larger) stirred tank contactors to which are added appropriate amounts of sodium TPB, monosodium titanate (MST), process water, and recycle precipitate wash water to achieve an appropriate balance of all species.

\footnotetext{
${ }^{a}$ Modified in part from Bases, Assumptions and Results of the Flowsheet Calculations for the Short List Salt Disposition Alternatives, WSRC-RP-98-00168, October 5, 1998.
} 




Figure E-1. Flow diagram of the Small-Tank TPB process (WSRC-RP-98-00170, Vol. 1, Sec. 9, p. 114)

- Slurry leaving the last of the contactors is collected in a tank using an external filtration unit.

- The precipitate is washed and sent to the DWPF.

- Part of the wash solution is recycled to the first step above.

- The filtrate from which the cesium has been removed is combined with the remaining portion of the wash solution and sent to the Saltstone Facility for grout production.

The washed precipitate is hydrolyzed in the salt cell of the DWPF. The benzene is sent to the Consolidated Incineration Facility (CIF) and the remaining cesium containing solution goes to the Sludge Receipt and Adjustment Tank (SRAT) vessel of DWPF for mixing with sludge from the tank farms.

\section{E-1.1 Status of the Small-Tank TPB Alternative}

\section{E-1.1.1 Attributes}

The following key attributes support the technical feasibility of this alternative:

- The combined processing operations of removing strontium-90 and alpha emitters with monosodium titanate by adsorption and cesium with sodium TPB by precipitation in a train of three (or at a minimum two larger) stirred tank reactors has attractive processing features. Particularly, processing dilute suspensions is readily manageable in the chemical process industries. 
- Preliminary results suggest that low batch contact times ( $<1.5$ hours) can achieve satisfactory cesium decontamination levels with excess TPB at high agitation and $5 \mathrm{M}$ sodium concentrations of the salt solutions.

These results suggest a variation that increases the flexibility of the process alternative. Removal of strontium-90 and alpha emitters with MST can be performed separately from the Cs-137 removal by TPB. Major benefits include better process control of the Cs-137 precipitation operation with TPB, and reduced benzene generation resulting from TPB decomposition at $25^{\circ} \mathrm{C}$ with the shorter processing times.

- Process technology has been designed in flow sheets to safely accommodate the bounding benzene generation rates.

- The process flow sheet analysis indicates that throughput limitations occur, by design, due to DWPF processing rate capabilities.

- Work-off of TPB solids and solutions should be readily accommodated.

- Safety issues from benzene and hydrogen generation in the various reaction vessels are within the bounds defined by the SRS preliminary hazards evaluation and can be managed by appropriate engineering.

\section{E-1.1.2 R\&D Results}

A variety of on-going $R \& D$ results in response to Defense Nuclear Facilities Safety Board (DNFSB) recommendation 96-1 and work executed during Phase III support the small-tank TPB alternative design:

- Solubilities of cesium, potassium, and sodium tetraphenylborate were determined in salt solutions (WSRC-TR-96-0384, Rev. 0), and more accurate estimates were identified in recent work (WSRC-TR-98-00103, Rev. 0).

- Hydrogen generation from radiolysis of salt solutions by TPB solutions and slurries was determined (WSRC-TR-96-0109 other studies) and employed for design calculations.

- Bounding benzene generation rates from radiolysis of TPB were determined and employed in flowsheet estimations (DPST-86-390 and WSRC-TR-97-00403).

- Benzene generation from chemical decomposition of dilute (soluble) TPB was studied for cases with and without KTPB present, and in the filtrate (WSRC-TR-96-0351, Rev. 0; WSRC-TR-97-00403, Rev. 0; WSRC-RP-98-00298, Rev. 0; WSRC-TR-98-00250, Rev. 0).

- The kinetics of cesium precipitation by TPB were studied (WSRC-TR-98-00367, Rev. 0). The results suggest that cesium contamination levels of less than $30 \mathrm{nCi} / \mathrm{g}$ can be achieved for batch contact times of less than 1.5 hours at high mixing $(300 \mathrm{rpm})$ and $100 \%$ excess NaTPB for $5.0 \mathrm{M}$ sodium salt solutions.

- Studies on the degradation of solid TPB compounds were completed. The results form the partial basis for the proposed process flowsheets (WSRC-RP-98-00130, Rev. 0). 
- The kinetics of strontium, uranium, and plutonium adsorption with monosodium titanate show that 24-hour batch contacting may be needed for the slowest species, $\mathrm{Pu}$, to be removed to required levels. These results suggest that a train of three stirred tanks of approximately 30,000 gallons each would be needed to achieve continuous flow decontamination of these radionuclides (WSRC-TR-98-00347, Rev. 0).

- Explicit and extensive studies of catalytic and thermal decomposition of TPB salts on both simulants and actual wastes were made and the results were factored into defining temperature and residence time limits. Such studies include evaluation of benzene retention and release (WSRC-RP-98-00099, Rev. 0; WSRC-RP-98-00342, Rev. 0; WSRC-RP-9800130, Rev. 0; WSRC-RP-98-00232, Rev. 0; and WSRC-RP-97-00989, Rev. 0).

- Filtration studies on nonradioactive solids generated by the formation of TPB salts were investigated (USC-FRED-PSP-RPT-09-0-009, Oct. 1998; WSRC-TR-98-00250, Rev. 0; SRT-WHM-98-18, Rev. 0; SRT-WHM-98-17, Rev. 0; WHC-TR-98-00364, Rev. 0) at the University of South Carolina as well as the Savannah River Technology Center and were factored into the design.

- Summaries of the In-Tank Precipitation (ITP) work, planned and completed in response to DNFSB Recommendation 96-1, can be found in the DNFSB Implementation Plan (October 1996), Rev 0, and WSRC-RP-98-00300, Rev 0.

\section{E-1.1.3 Technology Gaps and R\&D Needs}

The following technology gaps with required $R \& D$ or engineering analysis are as follows: ${ }^{b}$

- The kinetics of cesium precipitation with TPB and adsorption of strontium-90 and alpha emitters by MST are not adequately known and must be studied to resolve large uncertainties in process conditions.

- Continuous fluid processing of simultaneous removal of strontium-90 and alpha emitters with MST adsorption and radioactive cesium with TPB precipitation in a train of stirred tanks has not been demonstrated either with simulated salt slurries or actual wastes at the bench-scale or pilot-scale level. Similarly, continuous fluid processing for only Cs-137 by TPB precipitation needs to be demonstrated. Uncertainties of fluid mixing on solids suspension and mass transfer, impact of nonideal mixing on extended residence times, and impact of trace contaminants, for example, on process efficiencies and benzene generation, are unresolved.

- There are uncertainties about the impact of trace contaminants that exist in real waste solutions on TPB decomposition and potential low cesium separation efficiencies (unacceptable decontamination factors) are unknown. Studies are necessary to determine the effects of soluble waste components variation on the precipitation and sorption reactions and subsequent TPB degradation kinetics.

\footnotetext{
'These and other R\&D needs are defined in the SE Team's "Applied Technology Scope of Work Matrix for Small-Tank TPB Precipitation," (HLW-SDT-980181, Rev. A).
} 
- There is added process complexity in the TPB flowsheet due to the salt cell required in DWPF to hydrolyze the TPB salts [MTPB] with formic acid/copper nitrate and the required benzene incineration by the Consolidated Incineration Facility. The processing characteristics in the salt cell have not been demonstrated under radioactive MTPB conditions and should be verified in the salt cell or at some intermediate scale.

- A strategy for safely working off accumulated ITP wastes must be explicitly developed with respect to accommodating them into the Small-Tank TPB alternative.

\section{E-1.2 General Conclusions}

Based on technical considerations, the Small-Tank TPB process is an acceptable alternative for use in the removal of radiocesium from salt wastes at SRS. The additional R\&D work completed to resolve the DFNSB recommendation 96-1 questions and recent Phase III studies provide adequate information to appropriately design for safe handling of benzene generated in the process and produce flow sheets to meet SRS permit requirements. Continuous operation of the three (or two) stirred vessels for the TPB precipitation/MST adsorption process should be demonstrated at least at bench-scale levels and desirably at pilot-scale levels before the alternative is acceptable. Although other design and process uncertainties exist, the additional science and technology studies listed above should resolve these issues.

The IPE Team finds fault in selecting an alternative that uses the inherently unstable precipitating agent TPB, which decomposes into flammable and hazardous benzene.

\section{E-2. CRYSTALLINE SILICONTITANATE NONELUTABLE ION EXCHANGE}

This proposed alternative would employ the engineered form of CST to remove radiocesium from the salt solution after removal of strontium-90 and alpha emitters by adsorption on MST. The CST is nonelutable; therefore, the loaded CST would be transferred to the DWPF to be combined with the washed sludge and frit for transfer to the glass melter. The resulting glass would have a higher titanium content than that presently produced. The decontaminated salt solution would go to the Saltstone Facility to be made into a Nuclear Regulatory Commission Class A grout waste form after treatment, if needed, to remove mercury.

The proposed process involves the following steps (see Figure E-2):

- MST is added to the HLW salt solutions to remove Sr-90 and alpha emitters to meet the Saltstone TRU limits.

- Filtration removes both the MST and any sludge entrained in the salt solution to prevent plugging of the ion exchange columns.

- Filtered solids are transferred to the DWPF for mixing with the sludge stream.

\footnotetext{
"Modified in part from "Bases, Assumptions and Results of the Flowsheet Calculations for the Short List Salt Disposition Alternatives,"WSRC-RP-98-00168, October 5, 1998.
} 




Figure E-2. Flow diagram for CST Ion Exchange (WSRC-RP-98-00170, Vol. 1, Sec.9, p. 110).

- The sludge stream and MST loaded with Sr-90 and alpha emitters are transferred to the DWPF for mixing with filtered solids and CST loaded with Cs.

- Ion Exchange in CST columns removes the Cs.

- The columns are washed to remove residual salts (to meet a DWPF sodium concentration specification).

- Transfer the decontaminated salt solution to mercury removal (GT-73 resin), if needed, and then to the Saltstone Facility for incorporation into grout. 


\section{E-2.1 Status of CST lon Exchange Alternative}

\section{E-2.1.1 Attributes}

The following attributes support the technical feasibility of this alternative:

- The ion-exchange operation is simple in principle, and there exists a wealth of operational knowledge within and outside the DOE Complex.

- The three-column carousel with reserve column system design is robust for the expected operation to accommodate the variation of feeds anticipated. Valuable operational experience exists and is being developed off site in addition to the expected WSRC Science and Technology program.

- A nonelutable ion exchange process has been demonstrated for cesium removal from salt solutions for cleanup at West Valley and Three Mile Island and at pilot scales at Melton Valley, ORNL, and Hanford as cited in SRS documentation. Also, cesium removal from 200,000 gallons of Melton Valley salt solutions is scheduled for FY 99, using CST ion exchange. Note that the chemical compositions of the salt solutions differ from those at SRS.

- Material properties of granular CST (IONSIV--IE911) appear to be satisfactory over process conditions evaluated. Initial transport studies indicate that granular CST can be sluiced into and from exchange columns, can be slurry transported long distances through pipes with centrifugal pumps, and does not form heels or plugs that cannot be dislodged. Preliminary studies also indicate that CST does not agglomerate due to packing in columns or deteriorate with exposure to process solutions at operational temperatures. Process equipment and pipe wear due to abrasion by CST is not likely to be problematic based on limited run time.

- Preliminary glass tests show that an operating window of compositions exists to produce durable CST/sludge glasses for expected CST ion exchange formulations with greater than $1.0 \mathrm{wt} \% \mathrm{TiO}_{2}$.

- The inclusion of the mercury ion exchange system is redundant due to projected blending (WSRC-RP-98-00168, p. 31) for CST Ion Exchange, Caustic Side Solvent Extraction, and Direct Disposal as Grout. Inclusion for CST Ion Exchange requires additional process vessels and low-level shielding plant layout space.

- This alternative assumes use of the Consolidated Incineration Facility though there is no documented need for organic material incineration. The cost impact should be subtracted from life cycle cost estimates.

- Safety issues from hydrogen generation from CST in the ion exchange columns and from both CST and sludge in the DWPF slurry treatment vessels are within the bounds defined by WSRC preliminary hazards evaluation and can be managed by appropriate engineering. 


\section{E-2.1.2 R\&D Results}

A variety of ongoing R\&D efforts executed during the Phase III selection period support the CST Ion Exchange alternative design:

- $\quad$ Studies (WSRC-TR-98-00344, Rev. 0) demonstrate support for reported cesium Kds on both simulant and actual waste samples formulated to represent SRS waste streams.

- Excellent modeling results by researchers at Texas $A$ and $M$ and Purdue Universities were used by the Salt Disposition Flowsheet Team for column design and conditions of operation (WSRC-TR-98-00343, Rev. 0).

- Based on short-term test data that did not fully simulate SRS salt waste solution composition, valuable studies were performed with flow loops at ORNL. These studies defined CST transport properties, including slurry transport velocities, conditions for CST plug removal, CST attrition, and level of CST abrasion (SRT-WHM-98-0019, Rev. 0).

- Hydrogen generation by radiolysis for fully loaded CST columns was studied (WSRC-RP98-01143) and indicate rates of one liter per minute at standard temperature and pressure for a water CST slurry, whereas for average composition simulated waste and CST slurry, the rate was four times smaller at 0.25 liter per minute.

- Hydrogen generation occurs in the SRAT tank of the DWPF cell from CST catalyzing formic acid decomposition. The rates of $\mathrm{H}_{2}$ generation fall below the DWPF design limits but could be troublesome. Foaming is more significant for this system than for sludge only (WSRC-TR-98-00297, Rev. 0).

- Data on MST loading with strontium-90 and alpha emitters were obtained and suggest the MST strike vessel size should be at least $50 \%$ greater than earlier design specifications (WSRC-TR-98-00347, Rev. 0).

- Preliminary glass tests show that amorphous glasses can be produced with MST/CST/sludge when $\mathrm{TiO}_{2}$ exceeds $1 \%$ (WSRC-RP-98-01131, Rev. 0), and that an operating window exists for producing durable CST/sludge glasses outside current model predictions (WSRC-RP-9801142, Rev. 0) and within expected CST ion exchange alternative formulations.

- Studies also were conducted that defined levels of Cs leaching at $80^{\circ} \mathrm{C}$ and suggest that some chemical deterioration of CST may occur. No SRS applicable data at $60-70^{\circ} \mathrm{C}$ are available to predict sorbent behavior at these temperatures (SRT-WHM-98-0019, Rev. 0). Chemical stability tests at Sandia (SAND 97-00771, April 1997, p. 29) show deterioration of CST to zeolite at $95^{\circ} \mathrm{C}$ in basic simulants (but not at $60^{\circ} \mathrm{C}$ ) and to anatase at 60 and $90^{\circ} \mathrm{C}$ in acidic solutions. Additional studies in this Sandia report on CST, IE-910, show slight decrease in Kds $(925$ to $825 \mathrm{ml} / \mathrm{g})$ with increase in temperature $\left(10^{\circ} \mathrm{C}\right.$ to $40^{\circ} \mathrm{C}$ for a simulant.

- The transport and store properties of CST slurries were extensively studied (SRT-WHM-980019, Rev. 0). 


\section{E-2.1.3 Technology Gaps and R\&D Needs}

The following technology gaps with required $R \& D$ or engineering analysis follows: ${ }^{d}$

- Studies are needed over operating conditions of interest (fluid temperature and compositions) to define the sorption kinetics and equilibria. Also, temperature effects on CST structure and subsequent effects on equilibria and processing need evaluation.

- Hydrogen bubbles generated by radiolysis in the column may cause cesium separation inefficiency due to pore blockage and channeling and should be examined.

- Carousel column design should be examined from all aspects to facilitate heat transfer, accommodate variability of flow conditions and fluid compositions, and ensure system operability (namely, sluicing operations, column replacement versus crane capacity, etc.).

- Sufficient testing must be performed to qualify a high titanium glass for HIW waste disposal.

- "Excessive" foaming in the slurry preparation tanks of DWPF needs to be evaluated and addressed. Such foaming provides a pathway for recycle of actinide-bearing sludge to the rest of the waste disposal system.

- Destruction of formic acid needs be evaluated. Such degradation of formate, either by hydrogen generating route or by chemical oxidation catalyzed by CST, could affect melter redox control and therefore glass quality.

- A strategy for safely working off accumulated ITP wastes must be explicitly discussed with respect to accommodating them into the CST Ion Exchange alternative.

- The use of existing facilities for some parts of this flow sheet needs to be evaluated.

\section{E-2.2 General Conclusions}

Based on technical considerations, the CST Ion Exchange process is an acceptable alternative for use in the removal of radiocesium from salt wastes at SRS. This alternative has sufficient technical maturity to proceed. Concerns on column operability and efficiency have to be addressed before the alternative is effective. Although technical, design, and operation uncertainties exist, additional science and technology studies should resolve these issues.

\section{E-3. CAUSTIC SIDE SOLVENT EXTRACTION}

The process uses a three-component organic mixture consisting of a calixarene-crown ether complex extractant (BoBcalix C6), a para-t-octyl-phenoxy perfluoro ethyl-based propyl alcohol modifier (Cs-3), and a hydrocarbon diluent Isopar L developed by scientists at Oak Ridge National Laboratory.

\footnotetext{
'These and other R\&D needs are, for the most part, defined in the SE Team's "Applied Technology Scope of Work Matrix for CST Nonelutable Ion Exchange," (HLW-SDT-980181, Rev. A).
} 
This extractant mixture removes the dissolved cesium from the alkaline salt medium. The cesium-free aqueous salt phase (raffinate) can be sent to the Saltstone facility for conversion to a Class $\mathrm{A}$ grouted waste form, after mercury removal if necessary. The cesium contained in the organic phase can then be stripped back into an aqueous phase, and the strip solution sent to DWPF for incorporation into glass with the sludge streams. The stripped solvent stream is cleaned of impurities and recycled. It is periodically replaced with new solvent.

The proposed process involves the following steps (see Figure E-3):

- MST is added in a batch process to the salt solution to remove $\mathrm{Sr}, \mathrm{Pu}$, and $\mathrm{U}$ to meet the Saltstone TRU limits.

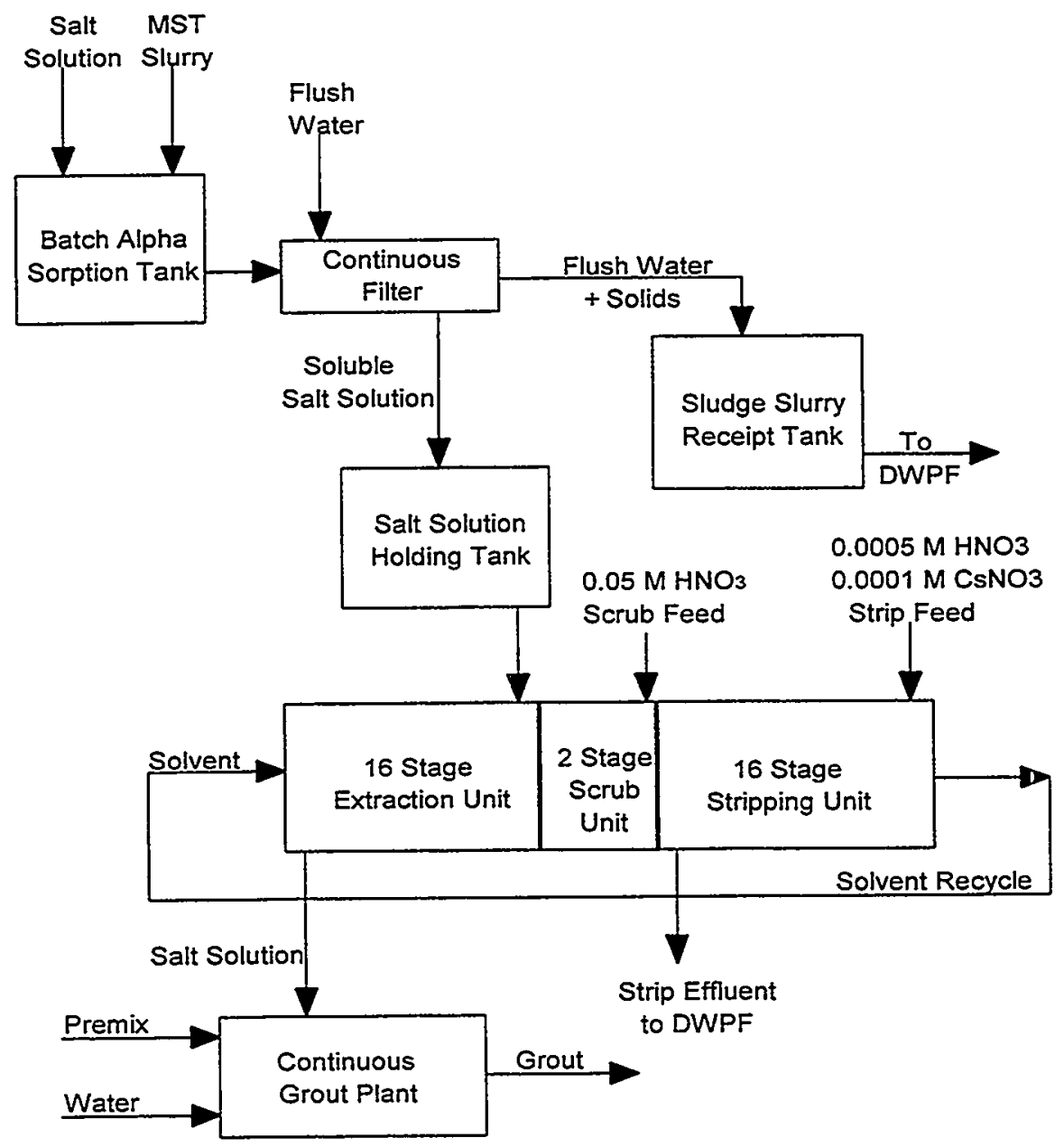

Figure E-3. Flow diagram of caustic side solvent extraction (WSRC-RP-98-00170, Volume 1, Sec. 9, p. 108).

\footnotetext{
"Modified in part from "Bases, Assumptions and Results of the Flowsheet Calculations for the Short List Salt Disposition Alternatives,"WSRC-RP-98-00168, October 5, 1998.
} 
- Filtration follows to remove both the MST and any sludge entrained in the salt solution. This step prevents formation of crud between the dispersed liquids generated in the centrifugal contactors.

- The filtered solids are transferred to the DWPF for mixing with the sludge stream.

- The filtered salt solution is fed to the centrifugal contactors to complete the extraction of the cesium. This involves extraction of the cesium into the organic solvent mixture, followed by stripping the cesium from the organic phase after it is separated from the decontaminated salt solution.

- The cesium-loaded (mildly acidic) strip solution would be transferred to DWPF for mixing with the washed sludge stream.

- The decontaminated salt solution from the extraction process would then be transferred to the Saltstone Facility. Mercury removal, if necessary, would be followed by conversion of the salt solution to a Class $\mathrm{A}$ grouted waste form.

\section{E-3.1 Status of Caustic Side Solvent Extraction Alternative}

\section{E-3.1.1 Attributes}

The following key attributes support the technical attractiveness of this alternative:

- Liquid extraction processes using centrifugal contactors have been used successfully in the DOE complex for radionuclide separations. The process has high engineering maturity and robustness and is safe to operate.

- The process produces a highly pure, concentrated cesium-137 product highly suitable as feed to the DWPF.

- The solvent extraction process is well suited to remote, large-scale, continuous operations.

- Much experience and expertise exists at SRS in operating solvent extraction processes.

- The process may be capable of accommodating large variations in feed compositions.

- Scale-up from bench- to plant-scale operation is well understood.

\section{E-3.1.2 R\&D Results}

A variety of $R \& D$ on the BoBcalixC6/Cs-3/Isopar L extractant system sponsored by DOE through the Efficient Separations Program and during the Phase III selection process provided information for the preconceptual design. These include the following: 
- A substantial study of the extractant system provides the fundamental database of cesium $\mathrm{Kds}$ over a range of conditions and also shows that the BoBcalix and $\mathrm{Cs}-3$ are sparingly soluble; acceptable losses of these components during operation is expected. ${ }^{f}$

- Distribution coefficients determined for two extraction, two scrub, and three strip contacts using SRS HLW yield an additional margin over those used in design calculations and suggest a conservative flow sheet design for the separators (WSRS-TR-98-00368, Rev. 0).

- Distribution coefficients strongly depend on temperature. They suggest a higher operating temperature for the stripping step $\left(30-37^{\circ} \mathrm{C}\right)$ and a lower temperature for the extraction step $\left(<25^{\circ} \mathrm{C}\right)$ (WSRC-TR-98-000370, Rev. 0, Conner et al., ANL, Appended Report). Temperature control of these stages is suggested.

- A small addition $(-10(-4) \mathrm{M}$ trioctyl amine) to the solvent drastically decreases the strip distribution coefficient and could be used to improve strip cycle performance.

- Tests show (WSRC-TR-98-00370, Rev. 0; WSRC-TR-98-00371, Rev.0) radiolytic degradation of BoBcalix is negligible under expected operating conditions, and $10 \%$ per year make-up is reasonable. The Cs-3 modifier showed $2 \%$ degradation per day. Both of these factors were incorporated into the design.

- Laboratory-scale continuous operation of centrifugal contactors suggests a design configuration of 17 extraction, 17 strip, and other appropriate ancillary stages, which concurs with the SRS design ${ }^{8}$ used in the process flow sheet.

\section{E-3.1.3 Technology Gaps and R\&D Needs}

It is the opinion of the IPE Team ${ }^{h}$ that this technology has substantial potential for cesium separation for the DOE Complex and that the work described below is warranted:

- The BoBcalix/Cs-3/Isopar L solvent extraction system has shown susceptibilities to trace contaminants, with potential major losses in cesium DFs. Studies with components in representative real salt solutions are required to determine the nature of these phenomena.

- Sustained continuous operation with continuous centrifugal contactors with real solutions should be demonstrated, preferably with real waste solutions, and at optimized controlled temperatures.

\footnotetext{
${ }^{\text {f }}$ Bruce A. Moyer et al., Oak Ridge National Laboratory, letter report to Walter Tamosaitis, Manager, Savannah River Technology Center, "Development of an Alkaline - side Cs SX Process applicable to Savannah River HLW using a Calixarene Crown Extractant: FY 98 Report," October 1, 1998.

${ }^{8}$ R. A. Leonard et al., "Evaluations of an Alkaline - Side Solvent Extractions Process for Cesium Removal from SRS Tank Waste using Laboratory - Scale Centrifugal Contragots," ANL RPT 1, Argonne National Laboratory, October 1998

${ }^{\mathrm{h}}$ The SE Team did not provide a technology scope work matrix for this alternative as this alternative was not selected.
} 
- The impact of trace metals on the efficiency and stability of the solvent system is unknown for both radionuclide and others.

- Long-term radiolytic stability testing of the solvent system under operating conditions is required to ensure expected stability of operation.

\section{E-3.2 General Conclusions}

Although the basic principles of solvent extraction have been long practiced in both nuclear and nonnuclear partioning operations, the solvent system selected to remove Cs from salt is technically immature. Longer development times are required for this alternative compared to the Small-Tank TPB and CST Ion Exchange alternative. Solvent availability and cost is an issue that will need to be faced to apply this solvent system to large-scale cesium removal from alkaline HLW.

\section{E-4. DIRECT DISPOSAL AS GROUT}

This process pretreats the salt solution with MST to remove strontium and alpha-emitters. The resulting solution containing all cesium is immobilized in a grout that is below Nuclear Regulatory Commission Class C LLW limits. The solidified waste would be disposed of in the Saltstone vaults on the Savannah River Site. In order to meet radiation protection standards, a new shielded and remotely operated and maintained production facility would need to be constructed. The sludge component of the waste would be processed in the DWPF.

The proposed process involves the following steps (see Figure E-4):i

- The salt solution is treated to remove soluble alpha-emitters contaminants and radiostrontium by adsorbing them in a 24 -hour time cycle on MST.

- The resulting slurry is filtered to remove the MST and any entrained HLW sludge.

- The solids are washed to remove dissolved entrained sodium salts.

- The solids are transferred to the DWPF for mixing with sludge in the Sludge Slurry Receipt Tank and subsequently vitrified.

- Filtrate from MST treatment is stored in the Salt Solution Holding Tank.

- If needed, mercury is removed using an ion exchange step.

- The filtrate is immobilized to produce grout for disposal.

- The clarified high cesium and sodium salt solution is diluted so that the final cesium concentrations do not exceed $4600 \mathrm{Ci}$ cesium-137 per cubic meter.

\footnotetext{
"Modified in part from "Bases, Assumptions and Results of the Flowsheet Calculations for the Short List Salt Disposition Alternatives," WSRC-RP-98-00168, October 5, 1998.
} 


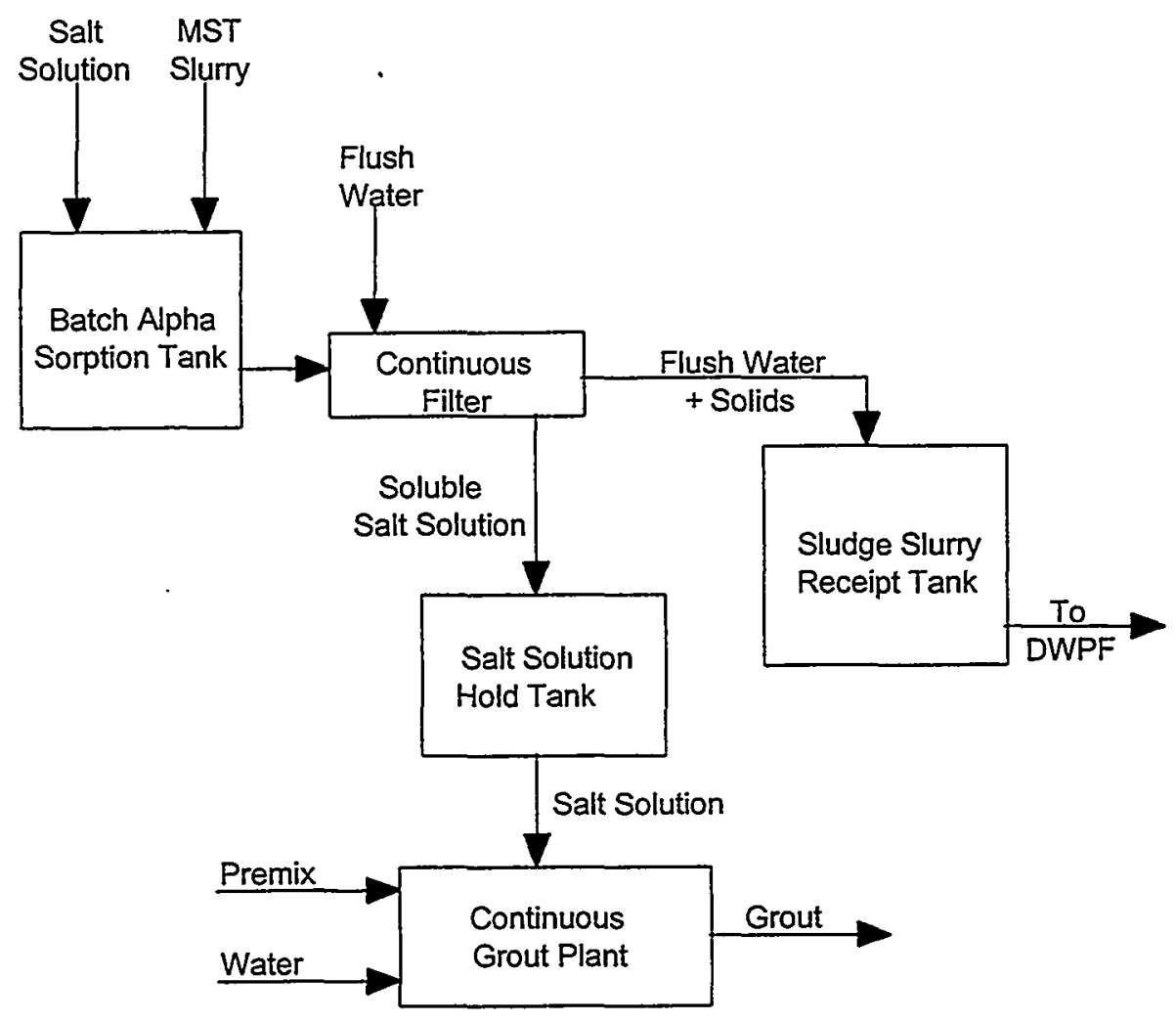

Figure E-4. Flow diagram for Direct Disposal as Grout (WSRC-RP-98-00170, Volume 1, Sec. 9).

\section{E-4.1 Status of Direct Disposal as Grout}

- From a technical perspective, this is the simplest and lowest cost alternative evaluated by the SE Team.

- The process flowsheet and plant layout is logical and well conceived and appears to satisfy the required material and composition flows.

\section{E-4.1.1 R\&D Results}

The $R \& D$ results to support this alternative during the Phase III selection process include the following:

- The grout composition is based on the same formulations being used in the current Saltstone Facility (WSRC-TR-98-00337, Rev. 0).

- Detailed thermal modeling and limited testing with simulants and actual waste have defined acceptable temperature limits for the grout vault (M-CLC-A-00144, Rev. A).

- Decay heat is only a minor contributor to the peak temperature reached within the waste (M-CLC-A-00144, Rev. A). 
- The importance of the long-lived cesium-135 to performance assessment releases was also evaluated and found not to be an issue (SRT-WED-98-0119, Rev. 0).

\section{E-4.1.2 Technology Gaps and R\&D Needs}

The following R\&D needs are identified:

- The effects of energy generation due to curing heat of reaction and radioactive decay of cesium-137 on grout properties have to be studied.

- The effects of radiolysis on hydrogen generation rates has to be evaluated.

- Studies are needed to ensure the integrity of the vaults for up to 500 years.

\section{E-4.2 Institutional Concerns}

The direct grout alternative poses significant institutional concerns. Institutional concerns would need to be addressed by DOE-Headquarters in coordination with other agencies. Since these institutional issues cannot be resolved by the SE Team or DOE-SR, this alternative is not viable at present. Even if resolution occurs, the time required would exceed the SE Team's salt removal schedule drivers.

The Saltstone product would need to be reclassified as incidental waste (from HLW), and to meet NRC limits for near-surface disposal of LLW. The need arises from legal, regulatory, and public perception issues.

The legal issue is the requirements for NRC licensing of disposal of DOE HLW, as stated in the Energy Reorganization Act of 1974. Thus, licensing would be required unless the NRC agrees that the high-cesium grout is incidental waste (non-HLW). The Nuclear Waste Policy Act of 1982 affirms this authority and contains language that allows the NRC to determine which "highly-radioactive" wastes are to be managed as HLW. In principle, DOE could proceed with licensing of high-cesium grout as $\mathrm{HLW}$, since there is no legal ban on near-surface disposal of HLW. However, the only facility currently authorized for HLW disposal is Yucca Mountain, so a new authorization for another facility would be needed. Revision of DOE Order 5820.2A (soon to be 435.1) would also be needed since DOE orders now require geologic disposal of HLW. In addition, 10 CFR 60 on HLW disposal applies only to geologic repository, so new rulemaking would be needed for a near-surface facility for HLW disposal.

\section{E-4.3 General Conclusions}

The SE Team defensibly eliminated the direct grout option because it has institutional and regulatory pitfalls and potential tank farms impacts. An aggressive DOE commitment would be required to resolve the expected institutional and stakeholder issues.

This option would require a full environmental impact statement because of the significant change from the previous NEPA envelope. The Saltstone grout containing the cesium must be reclassified as incidental waste from HLW by the NRC. Reclassification to incidental waste could require many years to be completed even when dealing with low levels of residual cesium.

The IPE Team considers this alternative a "high-risk" option in that the timeframe required to resolve the institutional issues could result in exceeding tank farm capacity. 


\section{Appendix F}

\section{Cost Evaluation}




$$
\text { F-2 }
$$




\section{Appendix F}

\section{F-1. COST EVALUATION}

\section{F-1.1 Introduction}

Specific items and issues relating to financial aspects of the SE Team evaluation were requested and evaluated. Those items are

- Cost Estimate Analysis

- HLW System ILC Estimate Analysis

- Cost Optimization

- Evaluation of Schedule

- Evaluation of Funding Profiles

- Evaluation of "Uncertainty" and Risk

- Evaluation of Bases of Estimates

- Evaluation of Cost Estimate Validity.

\section{F-1.1.1 Scope of Evaluation}

To assess the cost estimates, inputs to the estimating system, including the technical and financial bases of the estimates were tested for reasonableness. The WSRC estimating practices and supporting systems were observed and their products were examined. Work was done to determine the degree of process optimization for the alternatives. Schedule and funding profiles were examined and analyzed, evaluations of uncertainty and risk were conducted, and the degree to which the estimates are "valid" was determined. To accomplish the work described above, the financial and technical members of the IPE team coordinated the assessment of the SE Team report and supporting documentation.

\section{F-1.1.2 Source of Information}

1. The SE Team Final Selection Report

2. Supporting calculations from the HLW Systems plans generated in support of the SE Team Selection Report

3. HLW System Financial Model and Supporting Systems

4. HLW Production Model ("Prod-Mod") and Supporting Systems

5. Observations made during field trips to the Savannah River Site 
6. Interviews conducted with SE Team Members

7. Interviews conducted with WSRC HLW Division Management and Support Personnel

8. Interviews conducted with SE Team Consultants (Bechtel Corp. Construction Cost Estimators)

9. Individual IPE Team Technical Experts (Discussions, Reports, and Assessments)

10. Federal Energy Technology Center Publications regarding life cycle cost analysis

\section{F-1.2 Results of Examination of the SE Team Cost Estimates}

The SE Team provided in Table 7-14 of their final report the constant dollar LCC estimates of each of the four alternatives and their effects on the HLW System LCC. Table F-1 summarizes the estimates and delineates line item and operating funds for both the salt disposition alternatives and the HLW System incremental costs for each alternative

Table F-2 uses the information in Table F-1 to compare the Small-Tank TPB and CST Ion Exchange alternatives. The analysis is limited to these two alternatives because the Direct Disposal as Grout and Caustic Side Solvent Extraction options have been eliminated from further consideration.

The first item of comparison is the difference between the line item cost of the salt disposition alternatives. As shown in Table F-2, there is a \$127M difference favoring Small-Tank TPB over CST Ion Exchange for line item project costs, which occur in the first years of the project. When operations cost of the salt disposition alternatives are included, the difference favors CST Ion Exchange by \$123M. When the HLW System incremental costs are incorporated, the difference becomes $\$ 498 \mathrm{M}$ in favor of the CST Ion Exchange alternative. Taken together, the total differences in life cycle costs are $\$ 621 \mathrm{M}$ in favor of CST Ion Exchange. The difference between the alternatives is further increased when CIF operations

Table F-1. HLW system LCC estimates in constant FY-99 dollars (Amounts in Millions). (Source: Table 7-14 of WSRC-RP-98-00170.)

\begin{tabular}{|c|c|c|c|c|}
\hline $\begin{array}{c}\text { Cost Element } \\
\text { Salt Disposition Alternative }\end{array}$ & $\begin{array}{l}\text { Small } \\
\text { Tank }\end{array}$ & $\begin{array}{c}\text { Ion } \\
\text { Exchange } \\
\end{array}$ & $\begin{array}{c}\text { Solvent } \\
\text { Extraction }\end{array}$ & $\begin{array}{l}\text { Direct } \\
\text { Grout }\end{array}$ \\
\hline Project Cost/Line Item Funds & $\$ 1,167$ & $\$ 1,294$ & $\$ 1,485$ & $\$ 997$ \\
\hline Operations Cost & 750 & 500 & 989 & 678 \\
\hline Salt Disposition Alternative LCC & 1,917 & 1,794 & 2,474 & 1,675 \\
\hline HLW System Project/Line Item Funds & 841 & 842 & 840 & 839 \\
\hline HLW System Operations Costs & 9,290 & 8,791 & 8,816 & 8,073 \\
\hline Total HLW System Incremental Costs & 10,131 & 9,633 & 9,656 & 8,912 \\
\hline Total HLW LCC System Estimate & $\$ 12,048$ & $\$ 11,427$ & $\$ 12,130$ & $\$ 10,587$ \\
\hline
\end{tabular}


Table F-2. Comparative analysis (millions of constant dollars).

\begin{tabular}{|c|c|c|c|}
\hline Salt Disposition Alternative & Small Tank & $\begin{array}{c}\text { Ion } \\
\text { Exchange } \\
\end{array}$ & Difference \\
\hline Project Cost/Line Item Funds & $\$ 1,167$ & $\$ 1,294$ & $(\$ 127)$ \\
\hline Operations Cost & 750 & 500 & 250 \\
\hline Salt Disposition Alternative LCC & 1,917 & 1,794 & 123 \\
\hline HLW System Project/Line Item Funds & 841 & 842 & (1) \\
\hline HLW System Operations Costs & 9,290 & 8,791 & 499 \\
\hline Total HLW System Incremental Costs & 10,131 & 9,633 & 498 \\
\hline Total HLW LCC System Estimate & 12,048 & 11,427 & 621 \\
\hline CIF Life Cycle Operation Costs & 0 & (557) & 557 \\
\hline Adjusted LCC & $\$ 12,048$ & $\$ 10,870$ & $\$ 1,178$ \\
\hline
\end{tabular}

are recognized. The SE Team has confirmed that CIF operations of \$557M in LCC applies only to the Small- Tank TPB, not to the CST Ion Exchange alternative. Their inclusion of CIF operating costs in the CST Ion Exchange alternative estimates is inappropriate. Since CIF is not required for this alternative, adjustment of the CST Ion Exchange to exclude CIF but not Small-Tank TPB LCC brings the total difference to $\$ 1,178 \mathrm{M}$ in favor of the Ion Exchange alternative. The total difference is substantial in amount and contradicts the SE Team report, which states that cost is not a discriminating factor in the decision process.

\section{F-1.2.1 Evaluation of HLW System Incremental Cost}

HLW system incremental costs represent the cost effect of integrating the technical alternatives into the HLW system. In addition to the differences in construction and operating costs of the specific Salt Disposition facility, there are also schedule differences. Issues such as the date salt processing begins, the schedules for waste tank closure, waste tank removal, and completion of the waste removal program all materially impact the cost of each alternative. Importantly, the SE Team did consider the effects of system integration in development and evaluation of the four final technologies.

We examined the SE Team and HLW Divisions integration of the alternatives with other HLW system interfaces. Their analysis included throughput analysis and impacts on upstream and downstream processes with an emphasis on tank space management. WSRC computer simulation models appear capable of approximating real system impacts and quantifying those results as cost. Except for the continuing use of CIF incineration for the CST Ion Exchange and Direct Disposal as Grout alternatives (see above), we take no exception to the estimates based on the SE Team's evaluation of impacts to the HLW system. 


\section{F-1.3 Cost Optimization}

To ensure that alternatives are treated objectively and fairly, optimization opportunities that apply to multiple alternatives must be allowed to enter the affected cost estimates equally. Cost estimates resulting from this practice are comparable and result in useful information to DOE management.

The SE Team used the existing Salt Cell facility at DWPF for the Small-Tank TPB alternative, but not for the CST Ion Exchange alternative. At the conclusion of Phase III, the SE Team had not performed an evaluation of using the salt cell for partial implementation of the CST alternative. The amount of the difference was not quantified during the IPE review, as the anomaly was discovered too late to be incorporated in this report. We recommend that during conceptual design, the advantage of using existing facilities be explored and applied to both alternatives to ensure that costs are fairly evaluated and are comparable.

In addition to the above, we observed that the estimates were not optimized in general. While system sizing and operations were developed to ensure program completion in accordance with the FFA/CO and STP, the SE Team did not execute optimization exercises for purposes of their evaluation. For instance, the IPE technical evaluation of the Small-Tank TPB option revealed that vessel sizing was substantially understated based on mass balance and material flow calculations. A change of vessel size of this magnitude was expected to cause a substantial change in the plant layout and related costs. The SE Team had also discovered this anomaly. When asked how the vessel size would act to change the cost estimates, they stated that the facility layout had been sufficiently sized to accommodate the increased vessel requirements. The incremental cost for tank resizing, $\$ 15 \mathrm{M}$, was immaterial enough to be absorbed by applied contingency. This example indicates that the Small-Tank TPB facility is conservative in size and not optimized. A second example was disclosed by the SE Team during discussions held on December 3, 1998. This issue deals with sizing of CST Ion Exchange columns. $R \& D$ results indicate that the ion exchange columns may need to be substantially increased. However, restatement of cost was not needed as the preconceptual design was sufficiently sized to accommodate the increased column size requirements. As design of facilities becomes more refined in future periods, optimization can be expected to yield substantial estimated cost reductions, and more meaningful comparisons among competing alternatives can be made.

\section{F-1.4 Schedule}

Project schedules for each alternative were developed to ensure that the alternative will support tank space inventory management requirements based on DWPF operations schedules. This strategy is meant to fulfill FFA/CO and STP requirements for tank closure. Our observations of SRS discussions during field-work demonstrated that schedules were integrated among the HLW divisions. As reported by the SE Team, the schedules for all alternatives are extremely aggressive and do not contain provisions for schedule slip (contingency). Of primary concern for the two technologies selected to continue to the next phase, is the R\&D schedule that supports conceptual design. Unknown are issues surrounding chemical unit operations and engineering work for both Small-Tank TPB and CST Ion Exchange. We believe that critical $R \& D$ evaluations must occur prior to the final alternative selection. The risk involved is in advancing engineering prior to understanding the science associated with the solution and incurring unnecessary cost. The SE Team estimates that the cost of lengthening schedule ranges from $\$ 395 \mathrm{M} / \mathrm{yr}$ to $\$ 420 \mathrm{M} / \mathrm{yr}$ for the four options. We did not validate these amounts but realize that extended schedules will result in higher LCC. 


\section{F-1.5 Funding Profiles and Issues}

The salt disposition decision could severely impact currently projected Department of Energy (DOE) budgets. For FY-99 alone, if two alternatives are carried forward to the decision point, the SE Team estimates that an additional $\$ 68 \mathrm{M}$ would be needed in the Savannah River HLW Program. If two options were carried beyond FY-99, the FY-00 funding shortfall would be $\$ 302 \mathrm{M}$. If items listed as "Uncertainty" that are not schedule-related were to occur during either of these years, the impact would be higher.

Table F-3 details the fund deficits for each alternative by year using the accelerated clean up paths to closure (ACPC) as the baseline. Funds flow shown in the Table for each salt disposition alternative is from the supporting HLW system plan that supports the SE Team report. The ACPC has been adjusted to reflect a FY-99 \$25M incremental increase, and the current FY-00 Savannah River budget has replaced the published accelerated clean up paths to closure value for that year. The net effect of actual FY-99 funding adjustments were not known at the time of the writing of this report and have therefore not been included. Funding shortfalls have been calculated for CST Ion Exchange and Direct Disposal as Grout by removing the effects of operating the CIF incineration facility for years beyond FY-01, as these options do not use CIF.

Figure F-1 graphically represents the funding deficits for each alternative through FY-06 using the adjusted the ACPC as the baseline. As mentioned above, the net effect of actual FY-99 funding adjustments were not known at the time of writing of this report and have therefore not been included. Note that the funding shortfalls for CST Ion Exchange and Direct Disposal as Grout could be reduced in years subsequent to FY-00, since they are not expected to require CIF operations, and the HLW system would therefore not be required to continue incineration operations. If CIF continues operations for other than $\mathrm{HLW}$, the other waste forms using those services should bear the costs and not the HLW system.

\section{F-1.6 Evaluation of Risk and Uncertainty}

The SE Team, using accepted estimating practices, applied standard contingency to the LCC estimates. No exceptions were taken to the contingency applied to the LCC estimates prior to costs identified as "uncertainty."

While all cost estimates have some degree of uncertainty, the SE Team identified "Uncertainty" as an element of cost and defined it as a "... potential variance in the cost or schedule of an alternative." While the SE Team properly identified the need to assess events over which they have limited control or have insufficient current knowledge, their methods and treatment of uncertainty outside the HLW System LCC estimates resulted in total costs that could not be used to discriminate among competing alternatives. Table F-4 displays the relationships between the "Uncertainty" costs and the life cycle salt disposition alternative costs.

While the SE Team recognized that the chance of occurrence for all uncertainty items are not equally likely, they did not assess the likelihood of occurrence for each item during the preconceptual design phase. Therefore, uncertainties are likely to be overstated, and we could not determine the effect on the overall cost estimates. Costs associated with uncertainty range from about \$2B - \$4B dollars and are substantially higher than the combined LCC of facility and operations for each alternative. By applying a probability to each item, uncertainty would be more reasonably quantified and results more meaningful and comparable. The SE Team needs to take sufficient time to understand the uncertainties and to eliminate them and make amounts more comparable and reasonable. 
Table F-3. Adjusted funding profile analysis with modified accelerated cleanup paths to closure baseline HLW system escalated annual budget authority basis (Escalated Dollars-Amounts in Millions).

\begin{tabular}{|c|c|c|c|c|c|c|c|c|c|c|c|}
\hline Preparation Date: $11-17-98$ & $\begin{array}{c}\text { FY- } \\
99 \\
\end{array}$ & $\begin{array}{c}\text { FY- } \\
00\end{array}$ & $\begin{array}{c}\text { FY- } \\
01\end{array}$ & $\begin{array}{c}\text { FY- } \\
02 \\
\end{array}$ & $\begin{array}{c}F Y- \\
03\end{array}$ & $\begin{array}{c}\text { FY- } \\
04 \\
\end{array}$ & $\begin{array}{c}\text { FY- } \\
05 \\
\end{array}$ & $\begin{array}{c}\text { FY- } \\
06\end{array}$ & $\begin{array}{l}\text { Sub- } \\
\text { Total }\end{array}$ & $\begin{array}{l}\text { Out- } \\
\text { Years }\end{array}$ & $\begin{array}{c}\text { Total Life } \\
\text { Cycle }\end{array}$ \\
\hline Savannah River ACPC Baseline $^{c}$ & 455 & 447 & 613 & 659 & 643 & 658 & 605 & 620 & 4,700 & 8,457 & 13,157 \\
\hline Direct Grout - Funding Need & 479 & 591 & 635 & 734 & 777 & 780 & 654 & 627 & 5,277 & 9,348 & 14,625 \\
\hline Funding Shortfall W/O Uncertainty ${ }^{b}$ & (24) & $(144)$ & (22) & (75) & $(134)$ & (122) & (49) & (7) & $(577)$ & $(891)$ & $(1,468)$ \\
\hline Adjustment for $\mathrm{CIF}^{\mathrm{d}}$ & - & - & (27) & $(28)$ & (29) & (30) & (31) & (32) & (176) & $(576)$ & (753) \\
\hline Funding Shortfall After Considering CIF & $(24)$ & $(144)$ & 5 & $(47)$ & $(105)$ & $(92)$ & $(18)$ & 25 & $(401)$ & $(315)$ & $(715)$ \\
\hline Solvent Extraction - Funding Need & 496 & 616 & 701 & 737 & 787 & 856 & 770 & 676 & 5,639 & 11,425 & 17,064 \\
\hline Funding Shortfall W/O Uncertainty ${ }^{b}$ & $(41)$ & $(169)$ & (88) & (78) & (144) & (198) & $(165)$ & $(56)$ & $(9390$ & $(2,968)$ & $(3,907)$ \\
\hline Adjustment for $\mathrm{CIF}^{\mathrm{d}}$ & - & - & - & - & - & - & - & - & - & - & - \\
\hline Funding Shortfall After Considering CIF & (41) & $(169)$ & $(88)$ & (78) & $(144)$ & $(198)$ & $(165)$ & $(56)$ & (939) & $(2,968)$ & $(3,907)$ \\
\hline Small Tank TPB - Funding Need & 489 & 601 & 679 & 732 & 767 & 751 & 706 & 644 & 5,369 & 11,993 & 17,362 \\
\hline Funding Shortfall W/O Uncertainty ${ }^{b}$ & $(34)$ & $(154)$ & (66) & (73) & $(124)$ & (93) & $(101)$ & (24) & (669) & $(3,536)$ & $(4,205)$ \\
\hline Adjustment for $\mathrm{CIF}^{\mathrm{d}}$ & - & - & - & - & - & - & - & - & - & - & - \\
\hline Funding Shortfall After Considering CIF & $(34)$ & $(154)$ & (66) & (73) & $(124)$ & $(93)$ & $(101)$ & $(24)$ & $(669)$ & $(3,536)$ & $(4,205)$ \\
\hline CST Ion Exchange - Funding Need & 489 & 595 & 699 & 746 & 766 & 822 & 731 & 633 & 5,481 & 10,542 & 16,023 \\
\hline Funding Shortfall W/O Uncertainty ${ }^{b}$ & (34) & $(148)$ & (86) & (87) & $(123)$ & (164) & $(126)$ & (13) & (781) & $(2,085)$ & $(2,866)$ \\
\hline Adjustment for $\mathrm{CIF}^{d}$ & - & - & (27) & (28) & $(29)$ & (30) & (31) & $(32)$ & (176) & $(576)$ & (753) \\
\hline Funding Shortfall After Considering CIF & $(34)$ & $(148)$ & $(59)$ & (59) & (94) & (134) & $(95)$ & 19 & $(605)$ & $(1,509)$ & $(2,113)$ \\
\hline
\end{tabular}

${ }^{a}$ ACPC values were taken from the SRS HLW. System plan and have been adjusted for FY-99 to reflect a $\$ 25 \mathrm{M}$. Also, the FY-00 baseline values are updated to reflect the current estimates for that year.

'Estimated uncertainty costs were not scheduled by SRS; therefore, a presentation by year is not possible.

${ }^{c}$ The ACPC values reported are from the WSRC HLW Systems Plan at the 250 canisters of annual production level.

${ }^{d}$ Calculations include the reduction of CIF incineration operating funds for Direct Disposal as Grout and CST Ion Exchange, as neither of these options require the incineration process and should not be included in decisions based on cost. Elimination of CIF occurred in this analysis in FY-01. We assume that the time to effect discontinuance of CIF operations could not occur prior to FY-01. Even if CIF continues operations, it is inappropriate to penalize those options not requiring incineration. In the event incineration is required for other solid Savannah River waste forms, less expensive commercial options exist for this service. 


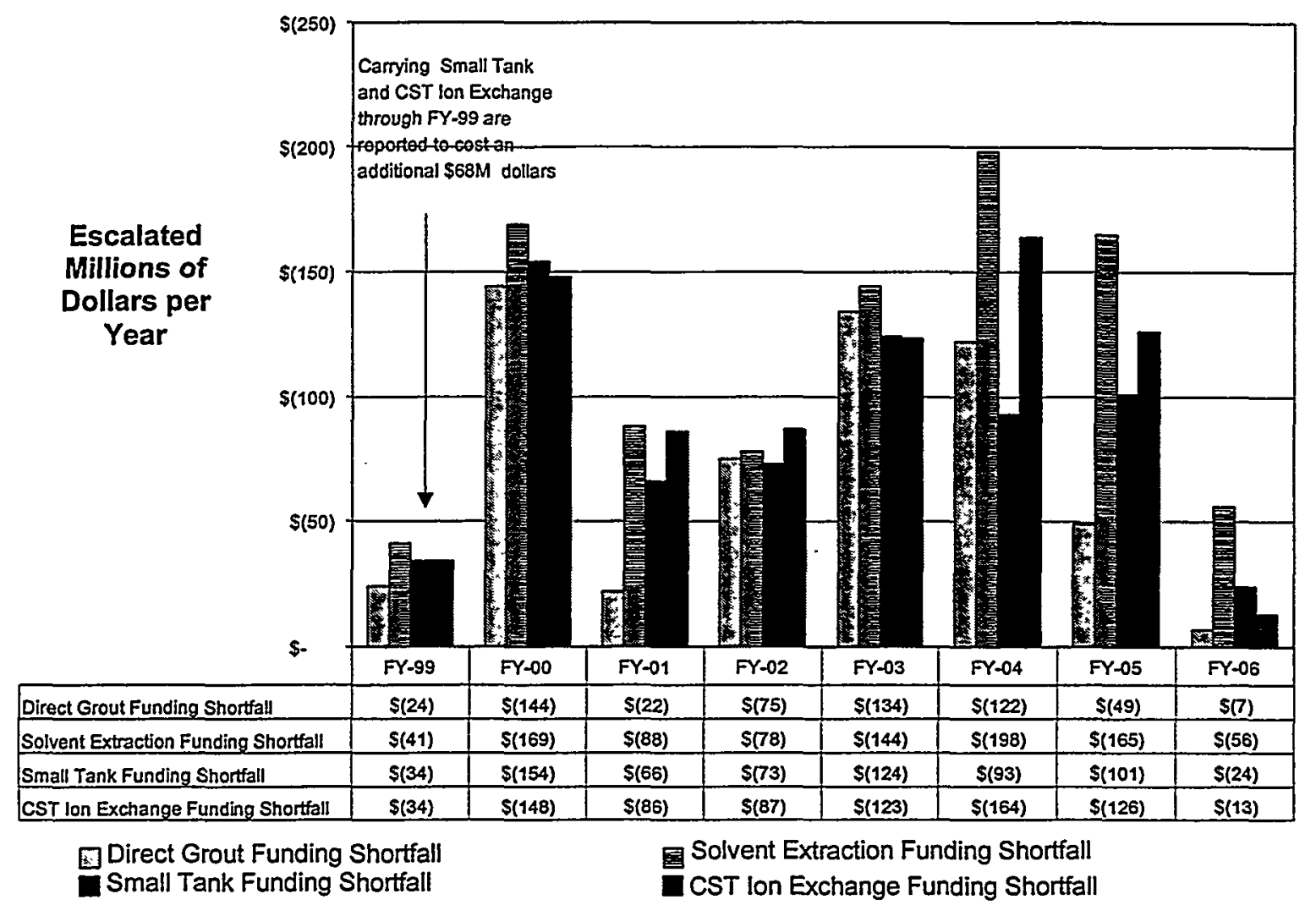

Figure F-1. SRS HIW system funding shortfalls.

Table F-4. Comparative analysis of cost, including uncertainty (Amounts in Millions of Constant FY-99. Dollars).

\begin{tabular}{|c|c|c|c|c|}
\hline Salt Disposition Alternative & $\begin{array}{c}\text { Small } \\
\text { Tank }\end{array}$ & $\begin{array}{c}\text { Ion } \\
\text { Exchange }\end{array}$ & $\begin{array}{c}\text { Solvent } \\
\text { Extraction }\end{array}$ & $\begin{array}{l}\text { Direct } \\
\text { Grout }\end{array}$ \\
\hline Project Cost/Line Item Funds & $\$ 1,167$ & $\$ 1,294$ & $\$ 1,485$ & $\$ 997$ \\
\hline Operations Cost & 750 & 500 & 989 & 678 \\
\hline Salt Disposition Alternative LCC & $\$ 1,917$ & $\$ 1,794$ & $\$ 2,474$ & $\$ 1,675$ \\
\hline Cost of Uncertainty & 1,961 & 2,358 & 2,600 & 3,940 \\
\hline Total Cost w/Uncertainty & $\$ 3,878$ & $\$ 4,152$ & $\$ 5,074$ & $\$ 5,615$ \\
\hline $\begin{array}{l}\text { Percent Uncertainty to Salt Disposition } \\
\text { Alternative LCC }\end{array}$ & $102 \%$ & $131 \%$ & $105 \%$ & $235 \%$ \\
\hline
\end{tabular}




\section{F-1.7 Evaluation of the Bases of the Estimates}

We assessed and tested the bases of the cost estimates and observed and evaluated the cost estimating systems. No material exceptions were taken to the estimating methodology, processes, or estimating systems used by SRS in developing LCC estimates for each alternative and the LCC HLW system estimates. Discussions of the bases of the estimates and results of the IPE review are presented below.

Cost estimates representing "uncertainty" issues are, for the most part, based on SE Team judgments. In many cases uncertainty relates to schedule. The schedule related estimates were calculated by multiplying estimated annual HLW system fixed costs by the years of anticipated delay. Included are such things as the time required to license grout as a waste form. We could not objectively evaluate the nature of the judgmental basis. For nonschedule-related "uncertainty" issues, the SE Team made a besteffort estimate that, again, included a "soft" basis such as professional experience. Because of the nature of the basis of uncertainty issues, they could not be objectively assessed. However, the use of professional, reasonable judgement is acceptable, especially with the limited data available during the preconceptual evaluation stage.

\section{F-1.7.1 Evaluation of the Bases of Estimates for Asset Construction (Total Project Cost).}

Total Project Cost (TPC) consists of the Total Estimated Cost (TEC) for constructing the facility and Other Project Cost (OPC), which includes research and development.

TEC comprises engineering, construction, project management, Savannah River Site overhead applications, and other support services costs. Engineering costs comprise design and systems engineering activities following conceptual design. Construction comprises labor, materials, equipment, and other items typically considered direct construction costs. Project management costs include project management, project controls, quality assurance, and other services required for management of the engineering and construction activities.

Other Project Costs (OPC) represent operational activities occurring prior to completion of construction, including laboratory process development costs. Also included are bench-scale testing, prototype testing, conceptual design, preparation of documentation, operational readiness reviews, and R\&D activities.

Our review of TEC included examination of SE Team cost data and observations of the estimating processes, practices, inputs, and results of their estimating systems.

\section{F-1.7.1.1 Evaluation of the Technical Bases of the Total Estimated Cost Estimate.} The bases of the estimate were technical assumptions used in developing the process flow-sheets and mass balance calculations. Process flow-sheets were then used to develop the facility design for each alternative. We reviewed the assumptions for technical reasonableness, traced the assumptions to the process flow-sheets, and tested mass balance calculations to ensure proper vessel size or any other technical issue that could substantially impact the cost estimates. We concluded that all facilities were conservatively sized. The conservative approach increased cost estimates but was fairly applied to all alternatives, resulting in excess capacity for all four. While this condition transiates into higher-thanprobable facility costs, at this phase of the process, none of the alternatives were unfairly discriminated against, and we considered the estimating rationale reasonable. 
F-1.7.1.2 Evaluation of the Financial Bases of the Total Estimated Cost Estimate. The financial bases of estimate that SRS used in developing TEC is reasonable. To price the technical inputs, the SE Team used independent estimators from the Bechtel company and a pricing model developed at the Hanford site. The model established unit pricing for construction materials and was applied to all four alternatives entering the selection phase.

\section{F-1.7.2 Evaluation of the Technical Bases of the OPC Estimates}

Direct OPC labor needs are based on an evaluation of human resource requirements from analyses of the process flow sheets and plant layout drawings. Resource needs were translated into terms of fulltime equivalent headcount (FTE) for each alternative. They then used the results of the estimated labor requirements in the other estimates of OPC (see below).

OPC support related requirements are based on parametric methods. Parametric estimating uses historical cost relationships from existing operations. The amount of training hours needed in relation to total direct operating hours is an example. The data are then adjusted for known differences and applied to the current situation. For the OPC estimate, the SE Team used identified relationships between support activities and direct operating labor hours from DWPF experience. There were no exceptions taken of the technical BOE used for the estimates. Use of parametric estimating practices are generally accepted in the absence of more refined data, which is generally the case during a preconceptual design phase.

F-1.7.2.1 Evaluation of the Financial Bases of the OPC Estimates. Direct labor costs were estimated using current Savannah River HLW System labor and overhead rates applied to the calculated number of FTEs. No exceptions were taken to the pricing data or methods used in developing the OPC cost estimates. Once more refined design and operating information becomes available during the conceptual design phase, more appropriate activity-based cost estimates can be developed.

\section{F-1.7.3 Evaluation of the Estimates of Operating and Maintenance Costs.}

Operations represent the direct costs associated with processing salt in the HLW system. Maintenance cost represents the upkeep of the building and its equipment.

F-1.7.3.1 Evaluation of the Technical Bases of the Operations and Maintenance Cost Estimates. The SE Team developed direct labor requirements by using the facility layout drawings. Once the headcount information was developed, direct staffing and supporting labor requirements were completed by calculating needs based on 12-hour rotating shifts. The IPE examination resulted in no exceptions to the technical bases of the estimates based on the preconceptual design information.

\section{F-1.7.3.2 Evaluation of the Financial Bases of the Operating and Maintenance Cost} Estimates. Pricing of operations and maintenance costs were based on current $\mathrm{HLW}$ system labor history. Pricing data for process materials were spot-checked. No exceptions were taken to the pricing methodology or data for labor. We found that some process chemical prices were based on outdated information. However, we do not consider the outdated price information to materially affect the preconceptual estimate.

\section{F-1.8 Evaluation of Cost Validity}

Validation represents execution of a planned, disciplined evaluation of financial forecasts. The purpose of the evaluation is to allow the expression of an opinion that the financial representations are either reasonable or unreasonable. To be able to express an unqualified opinion as to the reasonableness 
of the forecast, it must be based upon sufficient, mature, competent, and reliable cost data. Otherwise, the forecast is not defendable.

Because the SE Team cost estimates are based on preconceptual design information that is immature, we could not validate them. Nevertheless, we consider the estimates credible in context of the current immature design and technical data upon which they are based. This is true for both the individual alternative LCC estimates and the associated HLW system LCC estimates. Once the conceptual design phase is complete for these technologies, validatable cost estimates can be developed, properly evaluated, and defended. 